\title{
Risk, Uncertainty, and Expected Returns
}

\author{
Turan G. Bali and Hao Zhou*
}

\begin{abstract}
A conditional asset pricing model with risk and uncertainty implies that the time-varying exposures of equity portfolios to the market and uncertainty factors carry positive risk premia. The empirical results from the size, book-to-market, momentum, and industry portfolios indicate that the conditional covariances of equity portfolios with market and uncertainty predict the time-series and cross-sectional variation in stock returns. We find that equity portfolios that are highly correlated with economic uncertainty proxied by the variance risk premium (VRP) carry a significant annualized $8 \%$ premium relative to portfolios that are minimally correlated with VRP.
\end{abstract}

\section{Introduction}

This paper investigates whether the market price of risk and the market price of uncertainty are significantly positive and whether they predict the time-series and cross-sectional variation in stock returns. Although the literature has so far shown how uncertainty impacts optimal allocation decisions and asset prices, the results have been provided based on a theoretical model. ${ }^{1}$ Earlier studies do not pay attention to empirical testing of whether the exposures of equity portfolios

\footnotetext{
*Bali, tgb27@georgetown.edu, Georgetown University, McDonough School of Business, Washington, DC 20057; Zhou (corresponding author), zhouh@pbcsf.tsinghua.edu.cn, Tsinghua University, PBC School of Finance, Beijing 100083, PR China. We thank Ziemowit Bednarek, Geert Bekaert, Hendrik Bessembinder (the editor), Nick Bloom, Tim Bollerslev, John Campbell, Zhiyao Chen, Peter Christoffersen (the referee), John Cochrane, Frank Diebold, Paul Embrechts, Rob Engle, Tom Fearnley, Xavier Gabaix, Hui Guo, Laura Liu, Paulo Maio, Matt Pritsker, Adam Reed, Mark Seasholes, Mete Soner, Yi Tang, George Tauchen, Viktor Todorov, Andrea Vedolin, Robert Whitelaw, Liuren Wu, Hong Yan, Harold Zhang, Xiaoyan Zhang, and seminar participants at the 2013 American Finance Association Meeting, Cheung Kong Graduate School of Business, 2012 China International Conference in Finance, ETH-Zurich, 2012 Finance Down Under in Melbourne, Norwegian Business School, 2012 Singapore International Finance Conference at the National University of Singapore, and Swiss Finance Institute for helpful comments and suggestions.

${ }^{1}$ Although formal understanding of uncertainty and uncertainty aversion is poor, there exists a definition of uncertainty aversion originally introduced by Schmeidler (1989) and Epstein (1999). In recent studies, uncertainty aversion is defined for a large class of preferences and in different economic settings by Epstein and Wang (1994), Epstein and Zhang (2001), Chen and Epstein (2002), Klibanoff, Marinacci, and Mukerji (2005), Maccheroni, Marinacci, and Rustichini (2006), and Ju and Miao (2012). In addition to these theoretical papers, Ellsberg's (1961) experimental evidence demonstrates that the distinction between risk and uncertainty is meaningful empirically because people prefer to act on known rather than unknown or ambiguous probabilities.
} 
and individual stocks to uncertainty factors predict their future returns. We extend the original consumption-based asset pricing models to propose a conditional asset pricing model with time-varying market risk and economic uncertainty. According to our model, the premium on equity is composed of two separate terms; the first term compensates for the standard market risk, and the second term represents additional premium for variance risk. We test whether the time-varying conditional covariances of equity returns with market and uncertainty factors predict the time-series and cross-sectional variation in future stock returns.

In this paper, economic uncertainty is proxied by the variance risk premia in the U.S. equity market. Following Britten-Jones and Neuberger (2000), Jiang and Tian (2005), and Carr and Wu (2009), we define the variance risk premium (VRP) as the difference between expected variance under the risk-neutral measure and expected variance under the objective measure. ${ }^{2}$ We generate several proxies for financial and economic uncertainty and then compute the correlations between uncertainty variables and VRP. The first set of measures can be viewed as macroeconomic uncertainty proxied by the conditional variance of the U.S. output growth and the conditional variance of the Chicago Fed National Activity Index (CFNAI). The second set of uncertainty measures is based on the extreme downside risk of financial institutions obtained from the left tail of the time-series and cross-sectional distribution of financial firms' returns. The third uncertainty variable is related to the health of the financial sector proxied by the credit default swap (CDS) index. The last uncertainty variable is based on the aggregate measure of investors' disagreement about individual stocks trading at the New York Stock Exchange (NYSE), American Stock Exchange (AMEX), and National Association of Securities Dealers Automated Quotations (NASDAQ). We find that the variance risk premium is strongly and positively correlated with all measures of uncertainty considered in the paper. Our results indicate that VRP can be viewed as a sound proxy for financial and economic uncertainty.

Anderson, Ghysels, and Juergens (2009) introduce a model in which the volatility, skewness, and higher-order moments of all returns are known exactly, whereas there is uncertainty about mean returns. In their model, investors' uncertainty in mean returns is defined as the dispersion of predictions of mean market returns obtained from the forecasts of aggregate corporate profits. They find that the price of uncertainty is significantly positive and explains the cross-sectional variation in stock returns. Bekaert, Engstrom, and Xing (2009) investigate the relative importance of economic uncertainty and changes in risk aversion in the determination of equity prices. Distinct from the uncertainty that arises from disagreement among professional forecasters, Bekaert et al. (2009) focus on economic uncertainty proxied by the conditional volatility of dividend growth and find that both the conditional volatility of cash flow growth and time-varying risk aversion are important determinants of equity returns.

\footnotetext{
${ }^{2}$ Other studies (e.g., Rosenberg and Engle (2002), Bakshi and Madan (2006), Bollerslev, Gibson, and Zhou (2011), and Bekaert, Hoerova, and Duca (2013)) interpret the difference between the implied and expected volatilities as an indicator of the representative agent's risk aversion. Bollerslev, Tauchen, and Zhou (2009) and Drechsler and Yaron (2011) relate the variance risk premia to economic uncertainty risk.
} 
Different from the aforementioned studies, we propose a conditional asset pricing model in which economic uncertainty (proxied by VRP) plays a significant role along with the standard market risk. After introducing a 2-factor model with risk and uncertainty, we investigate the significance of risk-return and uncertainty-return coefficients using the time-series and cross-sectional data. Our empirical analyses are based on the size, book-to-market, momentum, and industry portfolios. We first use the dynamic conditional correlation (DCC) model of Engle (2002) to estimate equity portfolios' conditional covariances with the market portfolio and then test whether the conditional covariances predict future returns on equity portfolios. We find the risk-return coefficients to be positive and highly significant, implying a strongly positive link between expected return and market risk. Similarly, we use the DCC model to estimate equity portfolios' conditional covariances with the variance risk premia and then test whether the conditional covariances with VRP predict future returns on equity portfolios. The results indicate a significantly positive market price of uncertainty. Equity portfolios (individual stocks) that are highly correlated with uncertainty (proxied by VRP) carry a significant premium relative to portfolios that are uncorrelated or minimally correlated with VRP.

We also examine the empirical validity of the conditional asset pricing model by testing the hypothesis that the conditional alphas on the size, book-to-market, and industry portfolios are jointly 0 . The test statistics fail to reject the null hypothesis, indicating that the 2-factor model explains the time-series and crosssectional variation in equity portfolios. Finally, we investigate whether the model explains the return spreads between the high-return (long) and low-return (short) equity portfolios (Small-Big for the size portfolios, Value-Growth for the bookto-market portfolios, and HiTech-Telcm for the industry portfolios). The results from testing the equality of conditional alphas for high-return and low-return portfolios provide no evidence of a significant alpha for the Small-Big, ValueGrowth, and HiTech-Telcm arbitrage portfolios, indicating that the 2-factor model proposed in the paper provides both statistical and economic success in explaining stock market anomalies. Overall, the DCC-based conditional covariances capture the time-series and cross-sectional variation in returns on the size, book-to-market, and industry portfolios because the essential tests of the model are passed: i) there are significantly positive risk-return and uncertainty-return trade-offs; ii) the conditional alphas are jointly 0 ; and iii) the conditional alphas for high-return and low-return portfolios are not statistically different from each other. ${ }^{3}$ These results are robust when using an alternative specification of the time-varying conditional covariances with an asymmetric generalized autoregressive conditional heteroskedasticity $(\mathrm{GARCH})$ model, when using a larger cross section of equity portfolios in asset pricing tests, and after controlling for a wide variety of macroeconomic variables, market illiquidity, and credit risk. ${ }^{4}$

\footnotetext{
${ }^{3}$ We find significantly positive risk-return and uncertainty-return trade-offs in the cross section of momentum portfolios as well. However, the 2-factor model introduced in the paper rejects the hypotheses that i) the conditional alphas on momentum portfolios are jointly 0 , and ii) the conditional alphas for winner and loser portfolios are not statistically different from each other.

${ }^{4}$ Alternatively, our empirical result on VRP may be interpreted as compensating for the rare disaster risk (Gabaix (2012)), jump risk (Todorov (2010), Drechsler and Yaron (2011)), or tail risk
} 
Finally, we investigate the cross-sectional asset pricing performance of our model based on the 100 size and book-to-market (BM) portfolios. Using the longshort equity portfolios and the Fama-MacBeth (1973) regressions, we test the significance of a cross-sectional relation between expected returns on equity portfolios and the portfolios' conditional covariances (or betas) with VRP. Quintile portfolios are formed by sorting the 100 size/BM portfolios based on their VRP betas. The results indicate that the equity portfolios in the highest VRP-beta quintile generate $8 \%$ more annual raw returns and alphas compared with the equity portfolios in the lowest VRP-beta quintile. These economically and statistically significant return differences are also confirmed by the Fama-MacBeth crosssectional regressions, which produce positive and significant average slope coefficients on VRP beta.

The remainder of the paper is organized as follows: Section II presents the conditional asset pricing model with risk and uncertainty. Section III describes the data. Section IV outlines the estimation methodology. Section V presents the empirical results. Section VI investigates the cross-sectional asset pricing performance of our model. Section VII concludes the paper.

\section{Economic Motivation for VRP Factor}

To guide our economic interpretation of the main empirical finding in the paper, we follow the strategy of Campbell (1993), (1996) to substitute unobservable consumption-based measures with observable market-based measures. Under a structural model with recursive preference and consumption uncertainty (Bollerslev et al. (2009)), one can show that the two pricing factors (market return and VRP) span all systematic variations in any risky assets. Our methodology basically follows Campbell, Giglio, Polk, and Turley (2014) by substituting out the consumption growth in the pricing kernel, and then we substitute the unobservable economic uncertainty with the VRP.

\section{A. Implications from Consumption-Based Asset Pricing Model}

The representative agent in the economy is endowed with Epstein-Zin-Weil recursive preferences and has the value function $V_{t}$ of his or her lifetime utility as

$$
V_{t}=\left[(1-\delta) C_{t}^{\frac{1-\gamma}{\theta}}+\delta\left(\mathrm{E}_{t}\left[V_{t+1}^{1-\gamma}\right]\right)^{\frac{1}{\theta}}\right]^{\frac{\theta}{1-\gamma}},
$$

where $C_{t}$ is consumption at time $t, \delta$ denotes the subjective discount factor, $\gamma$ refers to the coefficient of risk aversion, $\psi$ equals the intertemporal elasticity of substitution (IES), and $\theta=(1-\gamma) /(1-1 / \psi)$. The key assumptions are that $\gamma>1$

(Bollerslev and Todorov (2011), Kelly (2014)). Alternatively, VRP can be generated from a habitformation model with sophisticated consumption dynamics (Bekaert and Engstrom (2010)). The finding may also be related to the expected business conditions (Campbell and Diebold (2009)) and their cross-sectional implications for stock returns (Goetzmann, Watanabe, and Watanabe (2009)). 
and $\psi>1$, and hence $\theta<0$. Consequently, the natural logarithm of the pricing kernel, $m_{t+1} \equiv \ln \left(M_{t+1}\right)$, may be expressed as

$$
m_{t+1}=\theta \ln \delta-\frac{\theta}{\psi} g_{t+1}+(\theta-1) r_{t+1},
$$

where $r_{t+1}$ is the return on the asset that pays the consumption endowment flow.

Suppose that log consumption growth and its volatility follow the joint dynamics

$$
\begin{aligned}
g_{t+1} & =\mu_{g}+\sigma_{g, t} z_{g, t+1}, \\
\sigma_{g, t+1}^{2} & =a_{\sigma}+\rho_{\sigma} \sigma_{g, t}^{2}+\sqrt{q_{t}} z_{\sigma, t+1}, \\
q_{t+1} & =a_{q}+\rho_{q} q_{t}+\varphi_{q} \sqrt{q_{t}} z_{q, t+1},
\end{aligned}
$$

where $\mu_{g}>0$ denotes the constant mean growth rate, $\sigma_{g, t+1}^{2}$ represents time-varying volatility in consumption growth, and $q_{t}$ introduces the volatilityuncertainty process in the consumption-growth process. ${ }^{5}$

Let $w_{t}$ denote the natural logarithm of the price-dividend or wealthconsumption ratio, and conjecture a solution for $w_{t}$ as an affine function of the state variables, $\sigma_{g, t}^{2}$ and $q_{t}$ :

$$
w_{t}=A_{0}+A_{\sigma} \sigma_{g, t}^{2}+A_{q} q_{t}
$$

We can solve for the coefficients $A_{0}, A_{\sigma}<0$, and $A_{q}<0$ using the standard Campbell and Shiller (1988) approximation $r_{t+1}=\kappa_{0}+\kappa_{1} w_{t+1}-w_{t}+g_{t+1}$. Substituting this equation into the pricing kernel in equation (2), we get

$$
m_{t+1}=\theta \ln \delta+\frac{\theta}{\psi} \kappa_{0}-\frac{\theta}{\psi} w_{t}+\frac{\theta}{\psi} \kappa_{1} w_{t+1}-\gamma r_{t+1},
$$

without referencing consumption growth, as in Campbell et al. (2014).

Suppose that asset returns have conditional joint lognormal distributions with time-varying volatility, then the risk premium on any asset $i$ is given by

$$
\mathrm{E}_{t}\left[r_{i, t+1}-r_{f, t}\right]+\frac{1}{2} \operatorname{Var}_{t}\left[r_{t+1}\right]=-\operatorname{Cov}_{t}\left[m_{t+1}, r_{i, t+1}\right] .
$$

Using the pricing kernel without consumption in equation (7), where the first three items are known at time $t$, we obtain the conditional asset pricing relation between the risk premium of any asset and the asset's covariances with the wealth return and time-varying shocks to future consumption:

$$
\begin{aligned}
\mathrm{E}_{t}\left[r_{i, t+1}-r_{f, t}\right]+\frac{1}{2} \operatorname{Var}_{t}\left[r_{t+1}\right]= & \gamma \operatorname{Cov}_{t}\left[r_{i, t+1}, r_{t+1}\right] \\
& -\frac{\theta}{\psi} \kappa_{1} \operatorname{Cov}_{t}\left[r_{i, t+1}, w_{t+1}\right],
\end{aligned}
$$

where $\gamma>1$ and $-(\theta / \psi) \kappa_{1}>0$.

\footnotetext{
${ }^{5}$ The parameters satisfy $a_{\sigma}>0, a_{q}>0,\left|\rho_{\sigma}\right|<1,\left|\rho_{q}\right|<1, \varphi_{q}>0$; and $\left\{z_{g, t}\right\},\left\{z_{\sigma, t}\right\}$, and $\left\{z_{q, t}\right\}$ are independent and identically distributed standard normal processes jointly independent with each other.
} 
One obvious advantage of Campbell's (1993), (1996) method is to substitute out consumption growth in the asset pricing tests, which also motivates using the market as a feasible proxy for total wealth. Furthermore, we substitute out the consumption growth volatility as well, using the result $\operatorname{Var}_{t}\left[r_{t+1}\right]=\sigma_{g, t}^{2}+$ $\kappa_{1}^{2}\left(A_{\sigma}^{2}+A_{q}^{2} \varphi_{q}^{2}\right) q_{t}$ from Bollerslev et al. (2009). Replacing $w_{t+1}$ with the wealthconsumption ratio in equation (6), we arrive at

$$
\begin{aligned}
& \mathrm{E}_{t}\left[r_{i, t+1}-r_{f, t}\right]+\frac{1}{2} \operatorname{Var}_{t}\left[r_{t+1}+\frac{\theta}{\psi} \kappa_{1} A_{\sigma} \operatorname{Cov}_{t}\left[r_{i, t+1}, \operatorname{Var}_{t+1} r_{t+2}\right]\right] \\
& =\gamma \operatorname{Cov}_{t}\left[r_{i, t+1}, r_{t+1}\right]+\frac{\theta}{\psi} \kappa_{1}\left[A_{\sigma} \kappa_{1}^{2}\left(A_{\sigma}^{2}+A_{q}^{2} \varphi_{q}^{2}\right)-A_{q}\right] \operatorname{Cov}_{t}\left[r_{i, t+1}, q_{t+1}\right] .
\end{aligned}
$$

Overlooking the Jensen's inequality term $\operatorname{Var}_{t} r_{t+1}$ and the high-order term $\operatorname{Cov}_{t}\left[r_{i, t+1}, \operatorname{Var}_{t+1} r_{t+2}\right]$, we can see that the risk-return trade-off $\gamma$ before $\operatorname{Cov}_{t}\left[r_{i, t+1}, r_{t+1}\right]$ is the risk-aversion coefficient and is positive, whereas the uncertainty-return trade-off $(\theta / \psi) \kappa_{1}\left[A_{\sigma} \kappa_{1}^{2}\left(A_{\sigma}^{2}+A_{q}^{2} \varphi_{q}^{2}\right)-A_{q}\right]$ before $\operatorname{Cov}_{t}\left[r_{i, t+1}, q_{t+1}\right]$ is not clearly signed, depending on the relative strength of $A_{\sigma}$ versus $A_{q}$. In fact, even if the risk-aversion coefficient is 0 , the uncertainty-return trade-off is still nonzero in general.

Finally, because the consumption volatility-of-volatility $q_{t}$ or economic uncertainty is not directly observable from the data, we follow the same spirit of Campbell et al. (2014) and substitute the unobservable uncertainty variable $q_{t}$ with the readily available VRP measure. Using the solution from Bollerslev et al. (2009) linking the variance risk premium $\left(\mathrm{VRP}_{t}\right)$ and the economic uncertainty variable $\left(q_{t}\right), \mathrm{VRP}_{t}=(\theta-1) \kappa_{1}\left[A_{\sigma}+A_{q} \kappa_{1}^{2}\left(A_{\sigma}^{2}+A_{q}^{2} \varphi_{q}^{2}\right) \varphi_{q}^{2}\right] q_{t}$, we reach our final result regarding the cross-sectional pricing implications from both risk and uncertainty proxies:

$$
\begin{aligned}
\mathrm{E}_{t}\left[r_{i, t+1}-r_{f, t}\right]+\frac{1}{2} \operatorname{Var}_{t}\left[r_{t+1}\right]+\frac{\theta}{\psi} \kappa_{1} A_{\sigma} \operatorname{Cov}_{t}\left[r_{i, t+1}, \operatorname{Var}_{t+1}\left[r_{t+2}\right]\right] \\
=\gamma \operatorname{Cov}_{t}\left[r_{i, t+1}, r_{t+1}\right] \\
\quad+\frac{\frac{\theta}{\psi} \kappa_{1}\left[A_{\sigma} \kappa_{1}^{2}\left(A_{\sigma}^{2}+A_{q}^{2} \varphi_{q}^{2}\right)-A_{q}\right]}{(\theta-1) \kappa_{1}\left[A_{\sigma}+A_{q} \kappa_{1}^{2}\left(A_{\sigma}^{2}+A_{q}^{2} \varphi_{q}^{2}\right) \varphi_{q}^{2}\right]} \operatorname{Cov}_{t}\left[r_{i, t+1}, \operatorname{VRP}_{t+1}\right] \\
\equiv A \cdot \operatorname{Cov}_{t}\left[r_{i, t+1}, r_{t+1}\right]+B \cdot \operatorname{Cov}_{t}\left[r_{i, t+1}, \operatorname{VRP}_{t+1}\right],
\end{aligned}
$$

where the risk-return trade-off coefficient $A \equiv \gamma$ and the uncertainty-return trade-off coefficient $B \equiv(\theta / \psi) \kappa_{1}\left[A_{\sigma} \kappa_{1}^{2}\left(A_{\sigma}^{2}+A_{q}^{2} \varphi_{q}^{2}\right)-A_{q}\right] /\left\{(\theta-1) \kappa_{1}\left[A_{\sigma}+\right.\right.$ $\left.\left.A_{q} \kappa_{1}^{2}\left(A_{\sigma}^{2}+A_{q}^{2} \varphi_{q}^{2}\right) \varphi_{q}^{2}\right]\right\}$. Note that the shocks to VRP and $q_{t}$ are proportional to each other and of the same sign, therefore carrying the same pricing information.

Campbell (1993) shows that, in an intertemporal capital asset pricing model (CAPM) setting as in Merton (1973), the appropriate choices for factors relevant in cross-sectional asset pricing tests should be the current market return and any other variables that have information about the future market returns. Given the recent evidence that the VRP possesses a significant forecasting power for shortterm market returns, our result derived previously regarding the cross-sectional asset pricing implication of the VRP is not surprising at all. Although the sign of the uncertainty-return trade-off coefficient $B$ is not determined for the general 
parameter setting, our empirical exercise finds it to be positive. The intuition for the positive slope coefficient $B$ is that investors dislike the reduced ability to hedge against a deterioration in the investment opportunity captured by the VRP, which positively predicts future market returns. Therefore investors require a higher return premium to hold the assets or stocks that positively covary with the VRP (Campbell (1996)).

Note that although we look at the cross-sectional pricing implication of the VRP, Ang, Hodrick, Xing, and Zhang (2006) investigate the cross-sectional pricing implication of the change in the option-implied volatility (VXO). These two approaches are closely related but also have important differences. The VXO is the option market implied volatility measure, whereas the VRP is the difference between implied and expected variances. Therefore, it is likely that, in the cross section, the VXO and the VRP perform differently in terms of beta pricing. Alternatively, the VRP's role in cross-sectional asset pricing may also be motivated from a systematic correlation risk factor, as noted by Buraschi, Trojani, and Vedolin (2014), where there is an equivalence between the correlation risk premium and the VRP (Driessen, Maenhout, and Vilkov (2009)).

Furthermore, the literature on index options typically finds a negative volatility risk premium driven by the negative correlation between the volatility shock and shock to market returns (see, among others, Bates (1996), Pan (2002), and Bakshi and Kapadia (2003)). In our consumption-based asset pricing model, although the shocks to consumption growth and volatility uncertainty are independent, the market return does contain a component driven by the consumption volatility uncertainty (Bollerslev et al. (2009)). Therefore, from a market-based model perspective, a VRP shock carries important information about the equity risk premium, the component due to economic uncertainty. In essence, the VRP is a much cleaner estimate of the uncertainty premium component in equity returns, and hence the strong pricing power of the VRP for cross-sectional stock returns. ${ }^{6}$

\section{B. Variance Risk Premia and Economic Uncertainty Measures}

For the option-implied variance of the Standard \& Poor's (S\&P) 500 market return, we use the end-of-month Chicago Board of Options Exchange (CBOE) volatility index on a monthly basis $\left(\mathrm{VIX}^{2} / 12\right)$. Following earlier studies, the daily realized variance for the S\&P 500 index is calculated as the summation of the 78 intraday 5-minute squared $\log$ returns from 9:30 AM to 4:00 PM, including the close-to-open interval. Along these lines, we compute the monthly realized variance for the S\&P 500 index as the summation of 5-minute squared log returns in a month. As discussed in Section A of the Internet Appendix (available at www.jfqa.org), the VRP at time $t$ is defined as the difference between the ex ante risk-neutral expectation and the objective or statistical expectation of the return variance over the $[t, t+1]$ time interval. The monthly VRP data are available from Jan. 1990 to Dec. 2012.

To give a visual illustration, Figure 1 plots the monthly time series of the level and change in the VRP. The VRP proxy is moderately high around the 1990

\footnotetext{
${ }^{6}$ We thank a referee for suggesting this interpretation.
} 


\section{FIGURE 1}

VRP Level and Change

Figure 1 plots the VRP or the implied-expected variance difference (Graph A) and the monthly change of VRP change (Graph B) for the market index from Jan. 1990 to Dec. 2012. The VRP is based on the realized variance forecast from lagged implied and realized variances. The shaded areas represent National Bureau of Economic Research (NBER) recessions.

Graph A. VRP Level

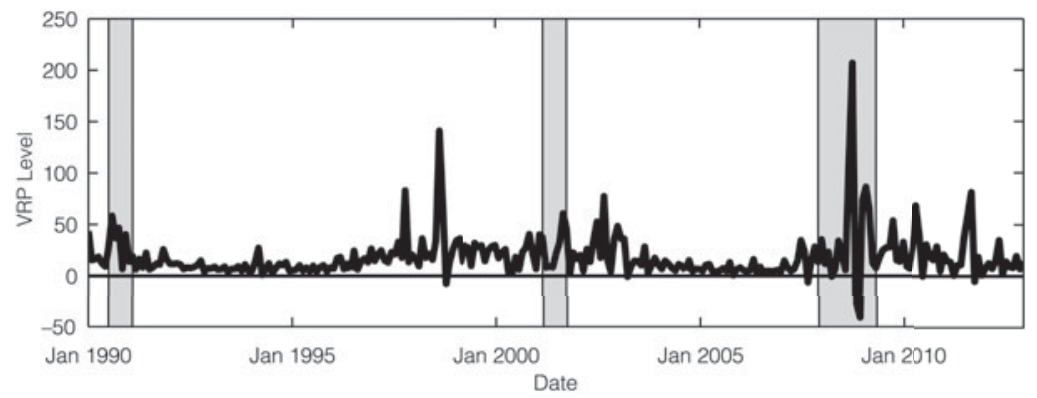

Graph B. VRP Change

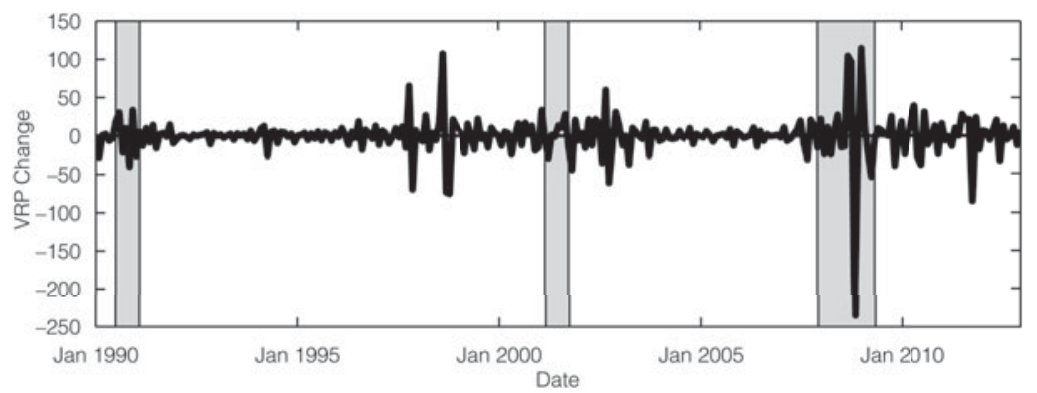

and 2001 economic recessions but much higher during the 2008 financial crisis and to a lesser degree around the 1997-1998 Asia-Russia-Long-Term Capital Management crisis. The variance spike during Oct. 2008 already surpasses the initial shock of the Great Depression in Oct. 1929. The huge run-up of the VRP in the fourth quarter of 2008 leads the equity market bottom being reached in Mar. 2009. The sample mean of the VRP is 18.47 (in percentages squared, monthly basis), with a standard deviation of 21.90 . Notice that the extraordinary skewness (3.76) and kurtosis (27.24) signal a highly non-Gaussian process for the VRP.

According to the conditional asset pricing specification, the VRP is viewed as a proxy for uncertainty. To test whether the VRP is in fact associated with alternative measures of uncertainty, we generate some proxies for financial and economic uncertainty. We obtain monthly values of the U.S. industrial production index from the G.17 database of the Federal Reserve Board and monthly values of the Chicago Fed National Activity Index (CFNAI) from the Federal Reserve Bank of Chicago for the period Jan. 1990-Dec. 2012. ${ }^{7}$ We use the GARCH(1,1)

\footnotetext{
${ }^{7}$ The CFNAI is a monthly index that determines increases and decreases in economic activity and is designed to assess overall economic activity and related inflationary pressure. It is a weighted
} 
model of Bollerslev (1986) to estimate the conditional variance of the growth rate of industrial production and the conditional variance of the CFNAI. These two measures can be viewed as macroeconomic uncertainty. The sample correlation between the VRP and economic uncertainty variables is positive and significant; the sample correlation is $53.28 \%$ with the variance of output growth and $31.01 \%$ with the variance of CFNAI.

Our second set of uncertainty measures is based on the downside risk of financial institutions obtained from the left tail of the time series and cross-sectional distribution of financial firms' returns (Allen, Bali, and Tang (2012)). Specifically, we obtain monthly returns for financial firms (Standard Industrial Classification (SIC) codes 6000-6999) for the sample period Jan. 1990-Dec. 2012. Then, the $1 \%$ nonparametric value-at-risk (VaR) measure in a given month is measured as the cutoff point for the lower 1 percentile of the monthly returns on financial firms. ${ }^{8}$ For each month, we determine the 1 percentile of the cross section of returns on financial firms and obtain an aggregate $1 \%$ VaR measure of the financial system for the period 1990-2012. In addition to the cross-sectional distribution, we use the time-series daily return distribution to estimate $1 \%$ VaR of the financial system. For each month from Jan. 1990 to Dec. 2012, we first determine the lowest daily returns on financial institutions over the past 1 to 12 months. The catastrophic risk of financial institutions is then computed by taking the average of these lowest daily returns obtained from alternative measurement windows. The estimation windows are fixed at 1 to 12 months, and each fixed estimation window is updated on a monthly basis. These two downside risk measures can be viewed as a proxy for uncertainty in the financial sector. The sample correlations between the VRP and financial uncertainty variables are positive and significant: $48.42 \%$ with the cross-sectional VaR measure and $38.73 \%$ with the time-series VaR measure.

The third uncertainty variable is related to the health of the financial sector proxied by the credit default swap (CDS) index. We download the monthly CDS data from Bloomberg. For the sample period Jan. 2004-Dec. 2012, we obtain monthly CDS data for Bank of America (BAC), Citigroup (C), Goldman Sachs (GS), JP Morgan (JPM), Morgan Stanley (MS), Wells Fargo (WFC), and American Express (AXP). Then, we standardize all CDS data to have 0 mean and unit standard deviation. Finally, we form the standardized equal-weighted CDS index (EWCDS) based on the equal-weighted average of standardized CDS values for the seven major financial firms. For the common sample period 2004-2012, the correlation between the VRP and the EWCDS is positive, 44.21\%, and highly significant.

The last uncertainty variable is based on the aggregate measure of investors' disagreement about individual stocks trading at the NYSE, AMEX, and NASDAQ. Following Diether, Malloy, and Scherbina (2002), we use dispersion in analysts'

average of 85 existing monthly indicators of national economic activity and is constructed to have an average value of 0 and a standard deviation of 1 . Because economic activity tends toward a trend growth rate over time, a positive index reading corresponds to growth above trend, and a negative index reading corresponds to growth below trend.

${ }^{8}$ Assuming that we have 900 financial firms in month $t$, the nonparametric measure of $1 \% \mathrm{VaR}$ is the ninth-lowest observation in the cross section of monthly returns. 
earnings forecasts as a proxy for divergence of opinion. It is likely that investors partly form their expectations about a particular stock based on the analysts' earnings forecasts. If all analysts are in agreement about expected returns, uncertainty is likely to be low. However, if analysts provide very different estimates, investors are likely to be unclear about future returns, and uncertainty is high. The sample correlation between the VRP and the aggregate measure of dispersion is about $15.23 \%$. Overall, these results indicate that the variance risk premia are strongly and positively correlated with all measures of uncertainty considered here. Hence, the VRP can be viewed as a sound proxy for financial and economic uncertainty.

\section{Data}

\section{A. Equity Portfolios}

We use the monthly excess returns on the value-weighted aggregate market portfolio and the monthly excess returns on the 10 value-weighted size, bookto-market, momentum, and industry portfolios. The aggregate market portfolio is represented by the value-weighted NYSE-AMEX-NASDAQ index. Excess returns on portfolios are obtained by subtracting the returns on the 1-month Treasury bill from the raw returns on equity portfolios. The data are obtained from Kenneth French's online data library. ${ }^{9}$ We use the longest common sample period available, from Jan. 1990 to Dec. 2012, yielding a total of 276 monthly observations.

Table I of the Internet Appendix presents the monthly raw return and CAPM alpha differences between high-return (long) and low-return (short) equity portfolios. The results are reported for the size, book-to-market (BM), momentum (MOM), and industry portfolios for the period Jan. 1990-Dec. 2012. ${ }^{10}$ The ordinary least squares (OLS) $t$-statistics are reported in parentheses. The Newey-West (1987) $t$-statistics are given in square brackets.

For the 10 size portfolios, "Small" (decile 1) is the portfolio of stocks with the smallest market capitalization, and "Big" (decile 10) is the portfolio of stocks with the biggest market capitalization. For the 1990-2012 period, the average return difference between the Small and Big portfolios is $0.31 \%$ per month with the OLS $t$-statistic of 1.02 and the Newey-West (1987) $t$-statistic of 0.99 , implying that small stocks on average do not generate higher returns than big stocks. In addition to the average raw returns, Table I of the Internet Appendix presents the intercept (CAPM alpha) from the regression of Small-Big portfolio return difference on a constant and the excess market return. The CAPM alpha (or abnormal return) for the long-short size portfolio is $0.25 \%$ per month with the OLS $t$ statistic of 0.84 and the Newey-West $t$-statistic of 0.80 . This economically and statistically insignificant alpha indicates that the static CAPM does explain the size effect for the 1990-2012 period.

\footnotetext{
${ }^{9}$ http://mba.tuck.dartmouth.edu/pages/faculty/ken.french/data_library.html

${ }^{10}$ Because the monthly data on variance risk premia start in Jan. 1990, our empirical analyses with equity portfolios and VRPs are based on the sample period Jan. 1990-Dec. 2012.
} 
For the 10 BM portfolios, "Growth" is the portfolio of stocks with the lowest $\mathrm{BM}$ ratios, and "Value" is the portfolio of stocks with the highest BM ratios. For the sample period Jan. 1990-Dec. 2012, the average return difference between the Value and Growth portfolios is economically and statistically insignificant; it is $0.23 \%$ per month with the OLS $t$-statistic of 0.77 and the Newey-West (1987) $t$-statistic of 0.69 , implying that value stocks on average do not generate higher returns than growth stocks. Similar to our findings for the size portfolios, the unconditional CAPM explains the value premium for the 1990-2012 period; the CAPM alpha (or abnormal return) for the long-short BM portfolio is only $0.21 \%$ per month with the OLS $t$-statistic of 0.69 and the Newey-West $t$-statistic of 0.54 .

For the 10 MOM portfolios, "Loser" (decile 1) is the portfolio of stocks with the lowest cumulative return over the previous 11 months (skipping the past 1 month), and "Winner" (decile 10) is the portfolio of stocks with the highest cumulative return over the previous 11 months. ${ }^{11}$ For the 1990-2012 period, the average return difference between the Loser and Winner portfolios is $1.05 \%$ per month with the OLS $t$-statistic of 2.05 and the Newey-West (1987) $t$-statistic of 1.91 , implying that winner stocks on average generate economically and statistically higher returns than loser stocks. In addition to the average raw returns, Table I of the Internet Appendix presents the CAPM alpha from the regression of Winner-Loser portfolio return difference on a constant and the excess market return. The CAPM alpha for the long-short MOM portfolio is $1.33 \%$ per month with the OLS $t$-statistic of 2.67 and the Newey-West $t$-statistic of 2.82. This economically and statistically significant alpha indicates that the static CAPM does not explain the momentum effect for the 1990-2012 period.

Similar to the size and value effects, the industry effect in the U.S. equity market is statistically weak over the past two decades. The average raw and risk-adjusted return differences between the high-return (HiTech) and low-return (Telcm) industry portfolios are statistically insignificant for the sample period 1990-2012.

Earlier studies, starting with Fama and French (1992), (1993), provide evidence for the significant size and value premia for the post-1963 period. Some readers may find the insignificant size and value premia for the 1990-2012 period controversial. Hence, in Table I of the Internet Appendix, we examine the significance of size and BM effects for the longest sample period of July 1926Dec. 2012 and the subsample period of July 1963-Dec. 2012. The results indicate significant raw return difference between the Value and Growth portfolios for both sample periods and significant risk-adjusted return difference (alpha) only for the post-1963 period. Consistent with the findings of earlier studies, we find significant raw return difference between the Small and Big stock portfolios for the 1926-2012 period, which becomes very weak for the post-1963 period. The CAPM alpha (or abnormal return) for the long-short size portfolio is economically and statistically insignificant for both sample periods.

\footnotetext{
${ }^{11}$ Following Jegadeesh and Titman (1993), the MOM variable for each stock in month $t$ is defined as the cumulative return on the stock over the previous 11 months starting 2 months ago (i.e., the cumulative return from month $t-12$ to month $t-2$ ).
} 


\section{Estimation Methodology}

Following Bali (2008) and Bali and Engle (2010), our estimation approach proceeds in steps:

1. We take out any autoregressive elements in returns and the VRP and estimate univariate GARCH models for all returns and VRPs.

2. We construct standardized returns and compute bivariate dynamic conditional correlation (DCC) estimates of the correlations between each portfolio and the market and between each portfolio and shock to the VRP using the bivariate likelihood function.

3. We estimate the expected return equation as a panel, with the conditional covariances as regressors. The error covariance matrix is specified as the seemingly unrelated regression (SUR). The panel estimation methodology with SUR takes into account heteroskedasticity and autocorrelation as well as contemporaneous cross-correlations in the error terms.

The following subsections provide details about the estimation of time-varying covariances and the estimation of time-series and cross-sectional relations between expected returns and risk and uncertainty.

\section{A. Estimating Time-Varying Conditional Covariances}

We estimate the conditional covariance between excess returns on equity portfolio $i$ and the market portfolio $m$ based on the mean-reverting DCC model:

$$
\begin{aligned}
R_{i, t+1} & =\alpha_{0}^{i}+\alpha_{1}^{i} R_{i, t}+\varepsilon_{i, t+1}, \\
R_{m, t+1} & =\alpha_{0}^{m}+\alpha_{1}^{m} R_{m, t}+\varepsilon_{m, t+1}, \\
\mathrm{E}_{t}\left[\varepsilon_{i, t+1}^{2}\right] & \equiv \sigma_{i, t+1}^{2}=\beta_{0}^{i}+\beta_{1}^{i} \varepsilon_{i, t}^{2}+\beta_{2}^{i} \sigma_{i, t}^{2}, \\
\mathrm{E}_{t}\left[\varepsilon_{m, t+1}^{2}\right] & \equiv \sigma_{m, t+1}^{2}=\beta_{0}^{m}+\beta_{1}^{m} \varepsilon_{m, t}^{2}+\beta_{2}^{m} \sigma_{m, t}^{2}, \\
\mathrm{E}_{t}\left[\varepsilon_{i, t+1} \varepsilon_{m, t+1}\right] & \equiv \sigma_{i m, t+1}=\rho_{i m, t+1} \cdot \sigma_{i, t+1} \cdot \sigma_{m, t+1}, \\
\rho_{i m, t+1} & =\frac{q_{i m, t+1}}{\sqrt{q_{i i, t+1} \cdot q_{m m, t+1}}}, \\
q_{i m, t+1} & =\bar{\rho}_{i m}+a_{1} \cdot\left(\varepsilon_{i, t} \cdot \varepsilon_{m, t}-\bar{\rho}_{i m}\right)+a_{2} \cdot\left(q_{i m, t}-\bar{\rho}_{i m}\right),
\end{aligned}
$$

where $R_{i, t+1}$ and $R_{m, t+1}$ denote the time $(t+1)$ excess return on equity portfolio $i$ and the market portfolio $m$ over a risk-free rate, respectively, and $\mathrm{E}_{t}[\cdot]$ denotes the expectation operator conditional on time- $t$ information; $\sigma_{i, t+1}^{2}$ is the time- $t$ expected conditional variance of $R_{i, t+1}, \sigma_{m, t+1}^{2}$ is the time- $t$ expected conditional variance of $R_{m, t+1}$, and $\sigma_{i m, t+1}$ is the time- $t$ expected conditional covariance between $R_{i, t+1}$ and $R_{m, t+1} ; \rho_{i m, t+1}=q_{i m, t+1} / \sqrt{q_{i i, t+1} \cdot q_{m m, t+1}}$ is the time- $t$ expected conditional correlation between $R_{i, t+1}$ and $R_{m, t+1}$; and $\bar{\rho}_{i m}$ is the unconditional correlation. To ease the parameter convergence, we use correlation targeting assuming that the time-varying correlations mean-revert to the sample correlations $\bar{\rho}_{\text {im }}$.

We estimate the conditional covariance between the excess return on each equity portfolio $i$ and the innovation in the variance risk premia, $\sigma_{i, \mathrm{VRP}}$, using an 
analogous DCC model:

$$
\begin{aligned}
& R_{i, t+1}=\alpha_{0}^{i}+\alpha_{1}^{i} R_{i, t}+\varepsilon_{i, t+1}, \\
& \mathrm{VRP}_{t+1}=\alpha_{0}^{\mathrm{VRP}}+\alpha_{1}^{\mathrm{VRP}} \mathrm{VRP}_{t}+\varepsilon_{\mathrm{VRP}, t+1}, \\
& \mathrm{E}_{t}\left[\varepsilon_{i, t+1}^{2}\right] \equiv \sigma_{i, t+1}^{2}=\beta_{0}^{i}+\beta_{1}^{i} \varepsilon_{i, t}^{2}+\beta_{2}^{i} \sigma_{i, t}^{2}, \\
& \mathrm{E}_{t}\left[\varepsilon_{\mathrm{VRP}, t+1}^{2}\right] \equiv \sigma_{\mathrm{VRP}, t+1}^{2}=\beta_{0}^{\mathrm{VRP}}+\beta_{1}^{\mathrm{VRP}} \varepsilon_{\mathrm{VRP}, t}^{2}+\beta_{2}^{\mathrm{VRP}} \sigma_{\mathrm{VRP}, t}^{2}, \\
& \mathrm{E}_{t}\left[\varepsilon_{i, t+1} \varepsilon_{\mathrm{VRP}, t+1}\right] \equiv \sigma_{i, \mathrm{VRP}, t+1}=\rho_{i, \mathrm{VRP}, t+1} \cdot \sigma_{i, t+1} \cdot \sigma_{\mathrm{VRP}, t+1} \text {, } \\
& \rho_{i, \mathrm{VRP}, t+1}=\frac{q_{i, \mathrm{VRP}, t+1}}{\sqrt{q_{i i, t+1} \cdot q_{\mathrm{VRP}, t+1}}}, \\
& q_{i, \mathrm{VRP}, t+1}=\bar{\rho}_{i, \mathrm{VRP}}+a_{1} \cdot\left(\varepsilon_{i, t} \cdot \varepsilon_{\mathrm{VRP}, t}-\bar{\rho}_{i, \mathrm{VRP}}\right) \\
& +a_{2} \cdot\left(q_{i, \mathrm{VRP}, t}-\bar{\rho}_{i, \mathrm{VRP}}\right) \text {, }
\end{aligned}
$$

where $\sigma_{i, \mathrm{VRP}, t+1}$ is the time- $t$ expected conditional covariance between $R_{i, t+1}$ and $\mathrm{VRP}_{t+1}^{\text {shock}}$, and $\rho_{i, \mathrm{VRP}, t+1}$ is the time- $t$ expected conditional correlation between $R_{i, t+1}$ and $\mathrm{VRP}_{t+1}^{\text {shock}}$. We use the same DCC model to estimate the conditional covariance between the market portfolio $m$ and the shock to the variance risk premia, $\sigma_{m, \mathrm{VRP}}$.

Equations (18), (19), and (22) indicate that the shock to the variance risk premia is obtained from a first-order autoregression $(\operatorname{AR}(1))$. Instead of using the change in the variance risk premia, $\Delta \mathrm{VRP}=\mathrm{VRP}_{t+1}-\mathrm{VRP}_{t}$, that restricts $\alpha_{0}^{\mathrm{VRP}}=0$ and $\alpha_{1}^{\mathrm{VRP}}=1$, we use a more general econometric specification to generate $\mathrm{VRP}_{t+1}^{\text {shock }}$ (i.e., $\alpha_{0}^{\mathrm{VRP}}$ and $\alpha_{1}^{\mathrm{VRP}}$ are estimated using the $\mathrm{AR}(1)$ specification in equation (19)).

We estimate the conditional covariances of each equity portfolio with the market portfolio and with $\mathrm{VRP}^{\text {shock }}$ using the maximum likelihood method described in the Internet Appendix (Section B). Then, as discussed in the following section, we estimate the time-series and cross-sectional relation between expected return and risk and uncertainty as a panel, with the conditional covariances as regressors.

At an earlier stage of the study, we use 10 equity portfolios and estimate in one step the time-varying conditional correlations as well as the parameters of the time-varying conditional mean in a multivariate GARCH-in-mean framework. To ease the parameter convergence, we use correlation targeting assuming that the time-varying correlations mean-revert to the sample correlations. To reduce the overall time of maximizing the conditional log likelihood, we first estimate all pairs of the bivariate GARCH-in-mean model and then use the median values of $A, B, a_{1}$, and $a_{2}$ as starting values along with the bivariate GARCH-in-mean estimates of variance parameters $\left(\beta_{0}, \beta_{1}, \beta_{2}\right)$. Even after going through these steps to increase the speed of parameter convergence, it takes a long time to obtain the full set of parameters in the multivariate GARCH-in-mean model. Similar to the findings of Bali and Engle (2010), the results from the 1-step estimation of 10 equity portfolios turn out to be similar to those obtained from the 2-step estimation procedure. $^{12}$

\footnotetext{
${ }^{12}$ Bali and Engle (2010) also estimate the risk-aversion coefficient in two steps; first they obtain the conditional covariances with DCC, and then they use the covariance estimates in the panel regression
} 


\section{B. Estimating Risk-Uncertainty-Return Trade-Off}

Given the conditional covariances, we estimate the portfolio-specific intercepts and the common slope estimates from the following panel regression:

$$
\begin{aligned}
R_{i, t+1}= & \alpha_{i}+A \cdot \operatorname{Cov}_{t}\left(R_{i, t+1}, R_{m, t+1}\right) \\
& +B \cdot \operatorname{Cov}_{t}\left(R_{i, t+1}, \operatorname{VRP}_{t+1}^{\text {shock }}\right)+\varepsilon_{i, t+1}, \\
R_{m, t+1}= & \alpha_{m}+A \cdot \operatorname{Var}_{t}\left(R_{m, t+1}\right) \\
& +B \cdot \operatorname{Cov}_{t}\left(R_{m, t+1}, \operatorname{VRP}_{t+1}^{\text {shock }}\right)+\varepsilon_{m, t+1},
\end{aligned}
$$

where $\operatorname{Cov}_{t}\left(R_{i, t+1}, R_{m, t+1}\right)$ is the time- $t$ expected conditional covariance between the excess return on portfolio $i\left(R_{i, t+1}\right)$ and the excess return on the market portfolio $\left(R_{m, t+1}\right), \operatorname{Cov}_{t}\left(R_{i, t+1}, \mathrm{VRP}_{t+1}^{\text {shock }}\right)$ is the time- $t$ expected conditional covariance between the excess return on portfolio $i$ and the innovation in the variance risk premia $\left(\mathrm{VRP}_{t+1}^{\text {shock }}\right), \operatorname{Cov}_{t}\left(R_{m, t+1}, \mathrm{VRP}_{t+1}^{\text {shock }}\right)$ is the time- $t$ expected conditional covariance between the excess return on the market portfolio $m$ and the variance risk premia $\left(\mathrm{VRP}_{t+1}^{\text {shock }}\right)$, and $\operatorname{Var}_{t}\left(R_{m, t+1}\right)$ is the time- $t$ expected conditional variance of excess returns on the market portfolio.

We estimate the system of equations in equations (24)-(25) using a weightedleast-square method that allows us to place constraints on coefficients across equations. We compute the $t$-statistics of the parameter estimates accounting for heteroskedasticity and autocorrelation as well as contemporaneous crosscorrelations in the errors from different equations. The estimation methodology can be regarded as an extension of the SUR method, the details of which are in the Internet Appendix (Section C).

\section{Empirical Results}

In this section we first present results from the 10 decile portfolios of size, book-to-market, momentum, and industry. Second, we discuss the economic significance of the 2-factor conditional asset pricing model at the market level. Finally, we provide a battery of robustness checks.

\section{A. Ten Decile Portfolios of Size, Book-to-Market, Momentum, and Industry}

The common slopes and the intercepts are estimated using the monthly excess returns on the 10 value-weighted size, book-to-market, momentum, and industry portfolios for the sample period Jan. 1990 to Dec. 2012. The aggregate stock market portfolio is measured by the value-weighted Center for Research in Security Prices (CRSP) index. Table 1 reports the common slope estimates $(A, B)$, the abnormal returns or conditional alphas for each equity portfolio $\left(\alpha_{i}\right)$ and the

with a common slope coefficient. In this setting, because the covariance matrices implied by the DCC model are not used in estimating risk premia or in computing their standard errors, a common worry in testing asset pricing models is that time-varying covariances are measured with error. Using different samples, they show that the significance of measurement errors in covariances is small. Hence, the 1-step and 2-step estimation procedures generate similar slope coefficients and standard errors. 


\section{TABLE 1}

Ten Decile Size, Book-to-Market, Momentum, and Industry Portfolios

Table 1 reports the portfolio-specific intercepts and the common slope estimates from the following panel regression:

$$
\begin{aligned}
& R_{i, t+1}=\alpha_{i}+A \cdot \operatorname{Cov}_{t}\left(R_{i, t+1}, R_{m, t+1}\right)+B \cdot \operatorname{Cov}_{t}\left(R_{i, t+1}, \operatorname{VRP}_{t+1}^{\text {shock }}\right)+\varepsilon_{i, t+1}, \\
& R_{m, t+1}=\alpha_{m}+A \cdot \operatorname{Var}_{t}\left(R_{m, t+1}\right)+B \cdot \operatorname{Cov}_{t}\left(R_{m, t+1}, \operatorname{VRP}_{t+1}^{\text {shock }}\right)+\varepsilon_{m, t+1},
\end{aligned}
$$

where $\operatorname{Cov}_{t}\left(R_{i, t+1}, R_{m, t+1}\right)$ is the time-t expected conditional covariance between the excess return on portfolio $i\left(R_{i, t+1}\right)$ and the excess return on the market portfolio $\left(R_{m, t+1}\right), \operatorname{Cov}_{t}\left(R_{i, t+1}, \mathrm{VRP}_{t+1}^{\text {shock }}\right)$ is the time-t expected conditional covariance between the excess return on portfolio $i$ and the shock to the variance risk premia (VRP shock $)$, $\operatorname{Cov}_{t}\left(R_{m, t+1}, V_{R P}^{s h o c k}\right)$ is the time-t expected conditional covariance between the excess return on the market portfolio $m$ and the VRPshock and $\operatorname{Var}_{t+1}\left(R_{m, t+1}\right)$ is the time- $t$ expected conditional variance of excess returns on the market portfolio. The parameters and their $t$-statistics are estimated using the monthly excess returns on the market portfolio and the 10 decile size, book-to-market, momentum, and industry portfolios for the sample period from Jan. 1990 to Dec. 2012. The alphas $\left(\alpha_{i}\right)$ are reported for each equity portfolio, and the $t$-statistics are presented below in parentheses. The $t$-statistics are adjusted for heteroskedasticity and autocorrelation for each series and cross-correlations among the portfolios. The last four rows, respectively, show the common slope coefficients $\left(A\right.$ and $B$ ), the Wald ${ }_{1}$ statistics from testing the joint hypothesis $H_{0}: \alpha_{1}=\alpha_{2}=\ldots \alpha_{m}=0$, and the Wald $d_{2}$ statistics from testing the equality of alphas for high-return and low-return portfolios (Small vs. Big, Value vs. Growth, Winner vs. Loser, and HiTech vs. Telcm). The p-values of Wald 1

\begin{tabular}{|c|c|c|c|c|c|c|c|}
\hline Size & $\alpha_{i}, \alpha_{m}$ & $\mathrm{BM}$ & $\alpha_{i}, \alpha_{m}$ & MOM & $\alpha_{i}, \alpha_{m}$ & Industry & $\alpha_{i}, \alpha_{m}$ \\
\hline Small & $\begin{array}{l}0.0053 \\
(1.32)\end{array}$ & Growth & $\begin{array}{l}0.0039 \\
(1.01)\end{array}$ & Loser & $\begin{array}{l}-0.0038 \\
(-0.61)\end{array}$ & NoDur & $\begin{array}{l}0.0053 \\
(2.05)\end{array}$ \\
\hline 2 & $\begin{array}{l}0.0041 \\
(0.92)\end{array}$ & 2 & $\begin{array}{l}0.0046 \\
(1.39)\end{array}$ & 2 & $\begin{array}{l}0.0012 \\
(0.26)\end{array}$ & Durbl & $\begin{array}{l}0.0020 \\
(0.40)\end{array}$ \\
\hline 3 & $\begin{array}{l}0.0047 \\
(1.17)\end{array}$ & 3 & $\begin{array}{c}0.0054 \\
(1.67)\end{array}$ & 3 & $\begin{array}{l}0.0024 \\
(0.62)\end{array}$ & Manuf & $\begin{array}{l}0.0051 \\
(1.48)\end{array}$ \\
\hline 4 & $\begin{array}{l}0.0037 \\
(0.96)\end{array}$ & 4 & $\begin{array}{l}0.0062 \\
(1.87)\end{array}$ & 4 & $\begin{array}{c}0.0038 \\
(1.15)\end{array}$ & Enrgy & $\begin{array}{l}0.0060 \\
(1.75)\end{array}$ \\
\hline 5 & $\begin{array}{l}0.0047 \\
(1.24)\end{array}$ & 5 & $\begin{array}{l}0.0057 \\
(1.83)\end{array}$ & 5 & $\begin{array}{c}0.0032 \\
(1.04)\end{array}$ & HiTech & $\begin{array}{l}0.0028 \\
(0.52)\end{array}$ \\
\hline 6 & $\begin{array}{l}0.0045 \\
(1.28)\end{array}$ & 6 & $\begin{array}{l}0.0050 \\
(1.51)\end{array}$ & 6 & $\begin{array}{l}0.0033 \\
(1.13)\end{array}$ & Telcm & $\begin{array}{l}0.0012 \\
(0.33)\end{array}$ \\
\hline 7 & $\begin{array}{l}0.0048 \\
(1.40)\end{array}$ & 7 & $\begin{array}{l}0.0059 \\
(1.92)\end{array}$ & 7 & $\begin{array}{l}0.0043 \\
(1.53)\end{array}$ & Shops & $\begin{array}{l}0.0039 \\
(1.17)\end{array}$ \\
\hline 8 & $\begin{array}{l}0.0042 \\
(1.21)\end{array}$ & 8 & $\begin{array}{l}0.0056 \\
(1.80)\end{array}$ & 8 & $\begin{array}{l}0.0056 \\
(1.96)\end{array}$ & Hlth & $\begin{array}{l}0.0047 \\
(1.57)\end{array}$ \\
\hline 9 & $\begin{array}{l}0.0042 \\
(1.31)\end{array}$ & 9 & $\begin{array}{l}0.0067 \\
(2.02)\end{array}$ & 9 & $\begin{array}{c}0.0039 \\
(1.28)\end{array}$ & Utils & $\begin{array}{l}0.0046 \\
(1.83)\end{array}$ \\
\hline Big & $\begin{array}{l}0.0021 \\
(0.70)\end{array}$ & Value & $\begin{array}{l}0.0078 \\
(1.89)\end{array}$ & Winner & $\begin{array}{l}0.0075 \\
(1.74)\end{array}$ & Other & $\begin{array}{l}0.0025 \\
(0.68)\end{array}$ \\
\hline Market & $\begin{array}{l}0.0026 \\
(0.83)\end{array}$ & Market & $\begin{array}{l}0.0042 \\
(1.25)\end{array}$ & Market & $\begin{array}{l}0.0032 \\
(0.98)\end{array}$ & Market & $\begin{array}{l}0.0026 \\
(0.77)\end{array}$ \\
\hline A & $\begin{array}{l}2.7712 \\
(2.83)\end{array}$ & $A$ & $\begin{array}{l}2.5585 \\
(2.66)\end{array}$ & A & $\begin{array}{l}2.2345 \\
(2.08)\end{array}$ & A & $\begin{array}{l}3.4834 \\
(2.38)\end{array}$ \\
\hline B & $\begin{array}{l}0.0037 \\
(3.54)\end{array}$ & $B$ & $\begin{array}{l}0.0059 \\
(2.58)\end{array}$ & B & $\begin{array}{l}0.0030 \\
(2.17)\end{array}$ & B & $\begin{array}{l}0.0062 \\
(2.85)\end{array}$ \\
\hline Wald $_{1}$ & $\begin{array}{c}16.40 \\
{[12.69 \%]}\end{array}$ & Wald $_{1}$ & $\begin{array}{c}10.43 \\
{[49.22 \%]}\end{array}$ & Wald $_{1}$ & $\begin{array}{l}22.15 \\
{[2.33 \%]}\end{array}$ & Wald $_{1}$ & $\begin{array}{l}14.36 \\
{[21.37 \%]}\end{array}$ \\
\hline Wald $_{2}$ & $\begin{array}{c}1.07 \\
{[30.09 \%]}\end{array}$ & Wald $_{2}$ & $\begin{array}{c}1.68 \\
{[19.49 \%]}\end{array}$ & Wald $_{2}$ & $\begin{array}{c}4.98 \\
{[2.56 \%]}\end{array}$ & Wald $_{2}$ & $\begin{array}{c}0.20 \\
{[65.47 \%]}\end{array}$ \\
\hline
\end{tabular}
and Wald ${ }_{2}$ statistics are given in square brackets.

market portfolio $\left(\alpha_{m}\right)$, and the $t$-statistics of the parameter estimates. The last two

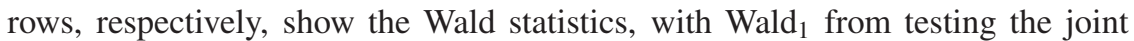
hypothesis $H_{0}: \alpha_{1}=\ldots=\alpha_{10}=\alpha_{m}=0$, and Wald 2 from testing the equality of conditional alphas for high-return and low-return portfolios (Small vs. Big; Value vs. Growth; Winner vs. Loser; and HiTech vs. Telcm). The $p$-values of the $\mathrm{Wald}_{1}$ and $\mathrm{Wald}_{2}$ statistics are given in square brackets.

The risk-aversion coefficient is estimated to be positive and highly significant for all equity portfolios: $A=2.77$ with a $t$-statistic of 2.83 for the size 
portfolios, $A=2.56$ with a $t$-statistic of 2.66 for the book-to-market portfolios, $A=2.23$ with a $t$-statistic of 2.08 for the momentum portfolios, and $A=3.48$ with a $t$-statistic of 2.38 for the industry portfolios. ${ }^{13}$ These results imply a positive and significant relation between expected return and market risk. ${ }^{14}$ Consistent with the conditional asset pricing specification, the uncertainty aversion coefficient is also estimated to be positive and highly significant for all equity portfolios: $B=0.0037$ with a $t$-statistic of 3.54 for the size portfolios, $B=0.0059$ with a $t$-statistic of 2.58 for the book-to-market portfolios, $B=0.0030$ with a $t$-statistic of 2.17 for the momentum portfolios, and $B=0.0062$ with a $t$-statistic of 2.85 for the industry portfolios. These results indicate a significantly positive market price of uncertainty in the aggregate stock market. Equity portfolios with higher sensitivity to increases in the variance risk premia are expected to generate higher returns in the next period.

One implication of the conditional asset pricing model is that the intercepts $\left(\alpha_{i}, \alpha_{m}\right)$ are not jointly different from 0 , assuming that the conditional covariances of equity portfolios with the market portfolio and the variance risk premia have enough predictive power for expected future returns. To examine the empirical validity of the conditional asset pricing model, we test the joint hypothesis

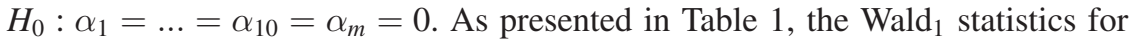
the size, book-to-market, and industry portfolios are, respectively, 16.40, 10.43, and 14.36 , with the corresponding $p$-values of $12.69 \%, 49.22 \%$, and $21.37 \%$. The significantly positive risk- and uncertainty-aversion coefficients and the insignificant Wald $_{1}$ statistics indicate that the 2 -factor model introduced in the paper is empirically sound.

We also investigate whether the model explains the return spreads between the Small and Big, Value and Growth, and HiTech and Telcm portfolios. The last row in Table 1 reports Wald $_{2}$ statistics from testing the equality of conditional alphas for high-return and low-return portfolios $\left(H_{0}: \alpha_{1}=\alpha_{10}\right)$. These intercepts capture the monthly abnormal returns on each portfolio that cannot be explained by the conditional covariances with the market portfolio and the variance risk premia.

The first column of Table 1 shows that the abnormal return on the small-stock portfolio is $\alpha_{1}=0.53 \%$ per month with a $t$-statistic of 1.32 , whereas the abnormal return on the big-stock portfolio is $\alpha_{10}=0.21 \%$ per month with a $t$-statistic of

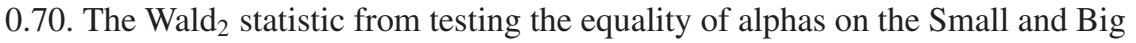
portfolios is 1.07 with a $p$-value of $30.09 \%$, indicating that there is no significant risk-adjusted return difference between the small-stock and big-stock portfolios. The second column provides the conditional alphas on the Value and Growth portfolios: $\alpha_{1}=0.39 \%$ per month with a $t$-statistic of 1.01 , and $\alpha_{10}=0.78 \%$ per month with a $t$-statistic of 1.89 . The Wald 2 statistic from testing $H_{0}: \alpha_{1}=\alpha_{10}$ is

\footnotetext{
${ }^{13}$ Our risk-aversion estimates ranging from 2.23 to 3.48 are very similar to the median level of risk aversion, 2.52, identified by Bekaert et al. (2009) in a different model.

${ }^{14}$ Although the literature is inconclusive on the direction and significance of a risk-return tradeoff, some studies do provide evidence supporting a positive and significant relation between expected return and risk (e.g., Bollerslev, Engle, and Wooldridge (1988), Ghysels, Santa-Clara, and Valkanov (2005), Guo and Whitelaw (2006), Guo and Savickas (2006), Lundblad (2007), Bali (2008), and Bali and Engle (2010)).
} 
1.68 with a $p$-value of $19.49 \%$, implying that the conditional asset pricing model explains the value premium (i.e., the risk-adjusted return difference between value and growth stocks is statistically insignificant). The last column shows that the conditional alphas on HiTech and Telcm portfolios are, respectively, $0.28 \%$ and $0.12 \%$ per month, generating a risk-adjusted return spread of 16 basis points (bps) per month. As reported in the last row, the $\mathrm{Wald}_{2}$ statistic from testing the significance of this return spread is 0.20 with a $p$-value of $65.47 \%$, yielding insignificant industry effect over the sample period 1990-2012.

We examine the empirical validity of the conditional asset pricing model for momentum portfolios by testing the hypothesis that the conditional alphas on

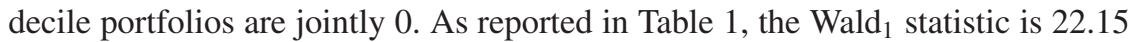
( $p$-value $=2.33 \%)$, implying that the conditional covariances of momentum portfolios with the market and the variance risk premia do not capture the entire timeseries and cross-sectional variation in expected returns of momentum portfolios. We also investigate whether the 2-factor model explains the return spreads between Winner and Loser portfolios. The Wald 2 statistic from testing the equality of conditional alphas, $\alpha_{1}=\alpha_{10}$, is 4.98 with a $p$-value of $2.56 \%$.

Overall, the DCC-based conditional covariances capture the time-series and cross-sectional variation in returns on the size, book-to-market, and industry portfolios because the essential tests of the conditional asset pricing model are passed: i) the risk-return and uncertainty-return trade-offs are significantly positive, ii) the conditional alphas are jointly 0 , and iii) the conditional alphas for high-return and low-return portfolios are not statistically different from each other. However, the statistically significant risk-adjusted return spread $\left(\alpha_{10}-\alpha_{1}\right)$ between Winner and Loser portfolios implies failure of the conditional asset pricing model in explaining the momentum effect.

\section{B. Economic Significance at the Market Level}

In this section, we test whether the risk-return $(A)$ and uncertainty-return $(B)$ coefficients are sensible and whether the uncertainty measure is associated with macroeconomic state variables.

Specifically, we rely on equation (25) and compute the expected excess return on the market portfolio based on the estimated prices of risk and uncertainty as well as the sample averages of the conditional covariance measures:

$$
\mathrm{E}_{t}\left[R_{m, t+1}\right]=\alpha_{m}+A \cdot \operatorname{Var}_{t}\left(R_{m, t+1}\right)+B \cdot \operatorname{Cov}_{t}\left(R_{m, t+1}, \operatorname{VRP}_{t+1}^{\text {shock }}\right)
$$

where $\alpha_{m}=0.0026, A=2.77$, and $B=0.0037$ for the 10 size portfolios; $\alpha_{m}=0.0042, A=2.56$, and $B=0.0059$ for the 10 book-to-market portfolios; $\alpha_{m}=0.0032, A=2.23$, and $B=0.0030$ for the 10 momentum portfolios; and $\alpha_{m}=0.0026, A=3.48$, and $B=0.0062$ for the 10 industry portfolios (see Table 1). The sample averages of $\operatorname{Var}_{t}\left(R_{m, t+1}\right)$ and $\operatorname{Cov}_{t}\left(R_{m, t+1}, \operatorname{VRP}_{t+1}^{\text {shock }}\right)$ are 0.002069 and -0.7426 , respectively. ${ }^{15}$ These values produce $\mathrm{E}_{t}\left[R_{m, t+1}\right]=0.56 \%$

\footnotetext{
${ }^{15}$ The negative value for the conditional covariance of the market return with the VRP factor is consistent with the consumption-based asset pricing model and the negative contemporaneous correlation between the market return and the VRP factor reported by Bollerslev et al. (2009).
} 
per month when the parameters are estimated using the 10 size portfolios, $\mathrm{E}_{t}\left[R_{m, t+1}\right]=0.51 \%$ per month when the parameters are estimated using the 10 book-to-market portfolios, $\mathrm{E}_{t}\left[R_{m, t+1}\right]=0.56 \%$ per month when the parameters are estimated using the 10 momentum portfolios, and $\mathrm{E}_{t}\left[R_{m, t+1}\right]=0.52 \%$ when the parameters are estimated using the 10 industry portfolios.

To evaluate the performance of our model with risk and uncertainty, we calculate the sample average of excess returns on the market portfolio, which is a standard benchmark for the market risk premium. The sample average of $R_{m, t+1}$ is found to be $0.53 \%$ per month for the period Jan. 1990-Dec. 2012, indicating that the estimated market risk premia of $0.51 \%-0.56 \%$ are very close to the benchmark. This again shows solid performance of the 2 -factor model introduced in the paper.

To further appreciate the economics behind the apparent connection between the VRP and the time-series and cross-sectional variations in expected stock returns, Figure 2 plots the VRP together with the monthly growth rate of real gross domestic product (GDP) per capita. As seen from the figure, there is a tendency for the VRP to rise in the month before a decline in GDP, whereas it typically narrows ahead of an increase in GDP. Indeed, the sample correlation equals -0.19 between lag VRP and current GDP (as first reported in Bollerslev et al. (2009)), with a standard error of 0.06 ( $p$-value $=0.13 \%)$. In other words, VRP as a proxy for economic uncertainty does seem to negatively relate to future macroeconomic performance.

\section{FIGURE 2}

VRP and GDP Growth

Figure 2 plots the growth rate of real GDP per capita (thin line) together with VRP (thick line) from Jan. 1990 to Dec. 2012. Both of the series are standardized to have mean 0 and variance 1. The shaded areas represent NBER recessions.

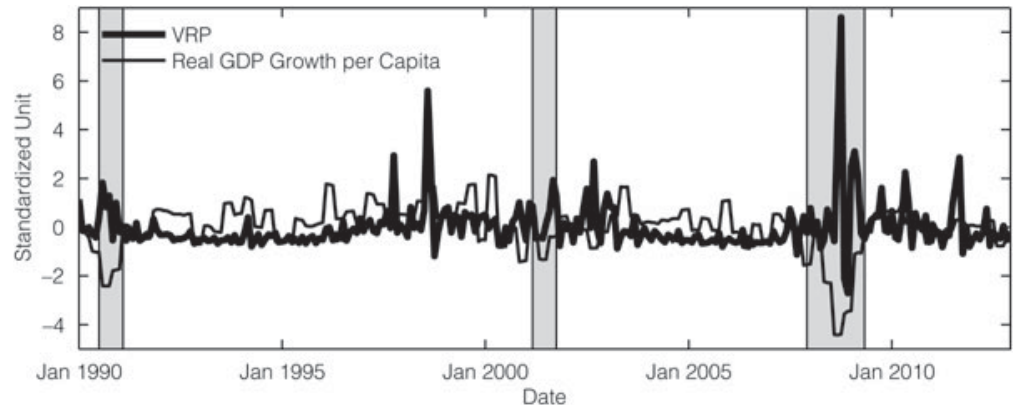

Thus, not only does the difference between the implied and expected variances positively covary with stock returns, it also covaries negatively with future growth rates in GDP. Intuitively, when VRP is high (low), it generally signals a high (low) degree of aggregate economic uncertainty. Consequently, agents tend to simultaneously cut (increase) their consumption and investment expenditures and shift their portfolios from more (less) to less (more) risky assets. This in turn results in a rise (decrease) in expected excess returns for stock portfolios that covary more (less) with the macroeconomic uncertainty, as proxied by the VRP. 
As mentioned earlier in Section II, we provide a 2-factor consumption-based asset pricing model in which the consumption growth and its volatility follow the joint dynamics, and hence the VRP affects expected future returns. In essence, our finding of a positive significant relation between the economic uncertainty measure and expected stock returns is consistent with the consumption-based model's implication that a heightened VRP does signal the worsening of macroeconomic fundamentals.

\section{Robustness Check}

We have so far provided evidence from the individual equity portfolios (10 size, 10 book-to-market, 10 momentum, and 10 industry portfolios). We now investigate whether our main findings remain intact if we use a joint estimation with all test assets simultaneously (total of 40 portfolios). Table 2 reports the parameter estimates and the $t$-statistics that are adjusted for heteroskedasticity and

\section{TABLE 2}

\section{Results from Pooled Data Set}

Table 2 reports the portfolio-specific intercepts and the common slope estimates from the following panel regression:

$$
\begin{aligned}
R_{i, t+1} & =\alpha_{i}+A \cdot \operatorname{Cov}_{t}\left(R_{i, t+1}, R_{m, t+1}\right)+B \cdot \operatorname{Cov}_{t}\left(R_{i, t+1}, \operatorname{VRP}_{t+1}^{\text {shock }}\right)+\varepsilon_{i, t+1}, \\
R_{m, t+1} & =\alpha_{m}+A \cdot \operatorname{Var}_{t}\left(R_{m, t+1}\right)+B \cdot \operatorname{Cov}_{t}\left(R_{m, t+1}, \operatorname{VRP}_{t+1}^{\text {shock }}\right)+\varepsilon_{m, t+1},
\end{aligned}
$$

where $\operatorname{Cov}_{t}\left(R_{i, t+1}, R_{m, t+1}\right)$ is the time- $t$ expected conditional covariance between the excess return on portfolio $i\left(R_{i, t+1}\right)$ and the excess return on the market portfolio $\left(R_{m, t+1}\right), \operatorname{Cov}_{t}\left(R_{i, t+1}, \mathrm{VRP}_{t+1}^{\text {shock }}\right)$ is the time- $t$ expected conditional covariance between the excess return on portfolio $i$ and the shock to the variance risk premia (VRP shock $_{t+1}$, $\operatorname{Cov}_{t}\left(R_{m, t+1}, V_{R P}^{s h o c k}\right)$ is the time- $t$ expected conditional covariance between the excess return on the market portfolio $m$ and $V_{R P}^{\text {shock }}$, and $\operatorname{Var}_{t}\left(R_{m, t+1}\right)$ is the time- $t$ expected conditional variance of excess returns on the market portfolio. The parameters and their $t$-statistics are estimated using the monthly excess returns on the market portfolio and the pooled data set of 10 decile size, book-to-market, momentum, and industry portfolios (total of 40 equity portfolios) for the sample period from Jan. 1990 to Dec. 2012. The $t$-statistics (below in parentheses) are adjusted for heteroskedasticity and autocorrelation for each series and cross-correlations among the portfolios. Table 2 shows the common slope coefficients $\left(A\right.$ and $B$ ), the Wald W $_{1}$ statistics from testing the joint hypothesis $H_{0}: \alpha_{1}=\alpha_{2}=\ldots \alpha_{m}=0$, and the Wald statistics from testing the equality of alphas for high-return and low-return portfolios (Small vs. Big, Value vs. Growth, Winner vs.

\begin{tabular}{|c|c|c|}
\hline & 1 & 2 \\
\hline & $A$ & $\begin{array}{l}3.1557 \\
(5.39)\end{array}$ \\
\hline & $B$ & $\begin{array}{l}0.0037 \\
(5.51)\end{array}$ \\
\hline Size & Wald $_{1}$ & $\begin{array}{c}9.80 \\
{[45.83 \%]}\end{array}$ \\
\hline Small vs. Big & Wald $_{2}$ & $\begin{array}{c}1.06 \\
{[30.43 \%]}\end{array}$ \\
\hline Book-to-Market & Wald $_{1}$ & $\begin{array}{c}4.93 \\
{[89.56 \%]}\end{array}$ \\
\hline Value vs. Growth & Wald $_{2}$ & $\begin{array}{c}0.89 \\
{[34.55 \%]}\end{array}$ \\
\hline Momentum & Wald $_{1}$ & $\begin{array}{l}19.28 \\
{[3.69 \%]}\end{array}$ \\
\hline Winner vs. Loser & Wald $_{2}$ & $\begin{array}{l}5.50 \\
{[1.91 \%]}\end{array}$ \\
\hline Industry & Wald $_{1}$ & $\begin{array}{c}11.27 \\
{[33.65 \%]}\end{array}$ \\
\hline HiTech vs. Telcm & Wald $_{2}$ & $\begin{array}{c}0.31 \\
{[57.99 \%]}\end{array}$ \\
\hline
\end{tabular}
Loser, and HiTech vs. Telcm). The $p$-values of Wald ${ }_{1}$ and Wald 2 statistics are given in square brackets. 
autocorrelation for each series and the cross-correlations among the error terms. As shown in the first row of Table 2, the risk-aversion coefficient is estimated to be positive and highly significant for the pooled data set at $A=3.16$ with a $t$-statistic of 5.39, implying a positive and significant relation between expected return and market risk. Similar to our earlier findings, the uncertainty-aversion coefficient is also estimated to be positive and highly significant for the joint estimation: $B=0.0037$ with a $t$-statistic of 5.51 . These results indicate a significantly positive market price of uncertainty when all portfolios are combined together. Equity portfolios with higher sensitivity to increases in the VRP are expected to generate higher returns in the next period.

The Wald 1 and Wald 2 statistics reported in Table 2 indicate that the conditional alphas on the size, book-to-market, and industry portfolios are jointly 0 , and the conditional alphas for high-return (Small, Value, HiTech) and low-return (Big, Growth, Telcm) portfolios are not statistically different from each other. Hence, the DCC-based conditional covariances capture the time-series and crosssectional variation in returns on the size, book-to-market, and industry portfolios. Similar to our earlier findings, the 2-factor model with risk and uncertainty provides both statistical and economic success in explaining stock market anomalies, except momentum.

As discussed in Section IV.A, we have so far used a more general econometric specification to generate $\mathrm{VRP}_{t+1}^{\text {shock }}$ instead of using the change in the variance risk premia. As shown in equation (18), the shock to variance risk premia is obtained from an $\mathrm{AR}(1)$ process. In this section, we use a simpler measure of $\mathrm{VRP}_{t+1}^{\text {shock }} \equiv \Delta \mathrm{VRP}_{t+1}=\mathrm{VRP}_{t+1}-\mathrm{VRP}_{t}$, which restricts $\alpha_{0}^{\mathrm{VRP}}=0$ and $\alpha_{1}^{\mathrm{VRP}}=1$ in equation (18). As presented in Table 3, the results from the change in VRP are very similar to those reported in Table 2 . The risk-aversion and uncertaintyaversion coefficients are estimated to be positive and highly significant at $A=3.03$ with a $t$-statistic of 4.65 and $B=0.0039$ with a $t$-statistic of 3.41 , indicating significantly positive market prices of risk and uncertainty. Consistent with our earlier findings, the $\mathrm{Wald}_{1}$ and $\mathrm{Wald}_{2}$ statistics reported in Table 3 indicate that the 2-factor model with risk and uncertainty provides both statistical and economic success in explaining stock market anomalies, except momentum.

In Section D of the Internet Appendix, we provide a battery of robustness checks. There appears to be some controversy in the econometrics literature around the consistency of maximum-likelihood parameter estimates generated by DCC models. ${ }^{16}$ To address this potential concern, in Section D.1 of the Internet Appendix, we use an alternative econometric methodology and estimate the conditional covariances based on the generalized conditional covariance (GCC) specification of Bali (2008). Table II of the Internet Appendix shows that the results from the GCC model are very similar to those reported in the paper. Second, we estimate the DCC-based conditional covariances using the asymmetric GARCH model of Glosten, Jagannathan, and Runkle (1993). Table III of the Internet Appendix shows that our main findings from the asymmetric GARCH

\footnotetext{
${ }^{16}$ See Aielli (2013), Caporin and McAleer (2013), and the proposed solution in Noureldin, Shephard, and Sheppard (2014).
} 
TABLE 3

Results from the Change in the Variance Risk Premia

Table 3 reports the portfolio-specific intercepts and the common slope estimates from the following panel regression:

$$
\begin{aligned}
R_{i, t+1} & =\alpha_{i}+A \cdot \operatorname{Cov}_{t}\left(R_{i, t+1}, R_{m, t+1}\right)+B \cdot \operatorname{Cov}_{t}\left(R_{i, t+1}, \Delta \operatorname{VRP}_{t+1}\right)+\varepsilon_{i, t+1}, \\
R_{m, t+1} & =\alpha_{m}+A \cdot \operatorname{Var}_{t}\left(R_{m, t+1}\right)+B \cdot \operatorname{Cov}_{t}\left(R_{m, t+1}, \Delta \operatorname{VRP}_{t+1}\right)+\varepsilon_{m, t+1},
\end{aligned}
$$

where $\operatorname{Cov}_{t}\left(R_{i, t+1}, R_{m, t+1}\right)$ is the time- $t$ expected conditional covariance between the excess return on portfolio $i$ $\left(R_{i, t+1}\right)$ and the excess return on the market portfolio $\left(R_{m, t+1}\right), \operatorname{Cov}_{t}\left(R_{i, t+1}, \Delta \mathrm{VRP}_{t+1}\right)$ is the time- $t$ expected conditional covariance between the excess return on portfolio $i$ and the change in the variance risk premia $\left(\Delta V R P_{t+1}\right)$, $\mathrm{Cov}_{t}\left(R_{m, t+1}, \Delta \mathrm{VRP}_{t+1}\right)$ is the time-t expected conditional covariance between the excess return on the market portfolio $m$ and $\Delta \operatorname{VRP}_{t+1}$, and $\operatorname{Var}_{t}\left(R_{m, t+1}\right)$ is the time-t expected conditional variance of excess returns on the market portfolio. The parameters and their $t$-statistics are estimated using the monthly excess returns on the market portfolio and the pooled data set of 10 decile size, book-to-market, momentum, and industry portfolios (total of 40 equity portfolios) for the sample period from Jan. 1990 to Dec. 2012. The $t$-statistics (below in parentheses) are adjusted for heteroskedasticity and autocorrelation for each series and cross-correlations among the portfolios. Table 3 shows the common slope coefficients

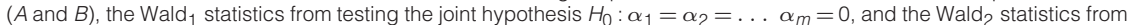
testing the equality of alphas for high-return and low-return portfolios (Small vs. Big; Value vs. Growth; Winner vs. Loser;

\begin{tabular}{|c|c|c|}
\hline & 1 & 2 \\
\hline & $A$ & $\begin{array}{l}3.0347 \\
(4.65)\end{array}$ \\
\hline & $B$ & $\begin{array}{l}0.0039 \\
(3.41)\end{array}$ \\
\hline Size & Wald $_{1}$ & $\begin{array}{c}6.70 \\
{[75.36 \%]}\end{array}$ \\
\hline Small vs. Big & Wald $_{2}$ & $\begin{array}{c}0.44 \\
{[50.67 \%]}\end{array}$ \\
\hline Book-to-Market & Wald $_{1}$ & $\begin{array}{c}4.36 \\
{[92.94 \%]}\end{array}$ \\
\hline Value vs. Growth & Wald $_{2}$ & $\begin{array}{c}0.55 \\
{[45.80 \%]}\end{array}$ \\
\hline Momentum & Wald $_{1}$ & $\begin{array}{l}21.45 \\
{[1.82 \%]}\end{array}$ \\
\hline Winner vs. Loser & Wald $_{2}$ & $\begin{array}{c}5.33 \\
{[2.09 \%]}\end{array}$ \\
\hline Industry & Wald $_{1}$ & $\begin{array}{c}11.27 \\
{[33.71 \%]}\end{array}$ \\
\hline HiTech vs. Telcm & Wald $_{2}$ & $\begin{array}{c}0.20 \\
{[65.42 \%]}\end{array}$ \\
\hline
\end{tabular}

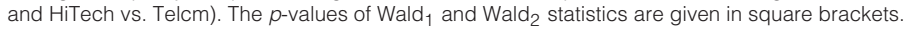

model are very similar to those reported in Table $1 .{ }^{17}$ Third, we examine whether the model's performance changes when we use a larger cross section of industry portfolios. Table IV of the Internet Appendix shows a significantly positive market price of uncertainty in the cross section of a large number of equity portfolios; portfolios with higher correlation with the shock to VRP generate higher returns in the next month for the value-weighted 17-, 30-, 38-, 48-, and 49industry portfolios. Also, the differences in conditional alphas are both economically and statistically insignificant, showing that the 2-factor model introduced in the paper provides success in explaining industry effects. Fourth, we provide robustness analysis when controlling for popular macroeconomic and financial variables. Table $\mathrm{V}$ of the Internet Appendix indicates that after controlling

\footnotetext{
${ }^{17}$ An alternative approach to estimating the risk-return coefficient for the stock market portfolio is introduced by Ghysels et al. (2005). An application of the mixed data sampling (or MIDAS) approach to conditional covariances in a panel-data setting represents an important direction for future research (see Ghysels, Sinko, and Valkanov (2006), Andreou, Ghysels, and Kourtellos (2010)).
} 
for variables associated with business conditions, the time-varying exposures of equity portfolios to the market and uncertainty factors carry positive risk premia. Fifth, we provide results from individual stocks trading at the NYSE, AMEX, and NASDAQ. Table VI of the Internet Appendix reports a significantly positive market price of uncertainty for large and liquid stocks trading in the U.S. equity market. Sixth, we test whether the predictive power of the variance risk premia is subsumed by the market illiquidity and/or credit risk. Table VII of the Internet Appendix clearly shows that controlling for the market illiquidity and default risk individually and simultaneously does not influence the significant predictive power of the conditional covariances of portfolio returns with the market risk and VRP factors. Finally, we test whether the conditional asset pricing model with risk and uncertainty outperforms the conditional CAPM in terms of statistical fit. Table VIII of the Internet Appendix presents the realized monthly average excess returns on equity portfolios and the cross section of expected excess returns generated by the 1-factor conditional CAPM and the 2-factor conditional asset pricing model. Clearly the newly proposed model with risk and uncertainty provides much more accurate estimates of expected returns on equity portfolios.

\section{Cross-Sectional Relation between VRP Beta and Expected Returns}

In this section, we investigate the cross-sectional asset pricing performance of our model by testing the significance of a cross-sectional relation between expected returns on equity portfolios and the portfolios' conditional covariances with VRP ${ }^{\text {shock }}$. Following Bali (2008) and Campbell et al. (2014), we use the size and book-to-market portfolios of Kenneth French as test assets. First, we estimate the DCC-based conditional covariances of 100 size/BM portfolios with VRP ${ }^{\text {shock}}$, and then for each month we form quintile portfolios sorted based on the portfolios' conditional covariances (or betas) with $\mathrm{VRP}^{\text {shock }}$. Because the conditional variance of $\mathrm{VRP}^{\text {shock }}$ is the same across portfolios, we basically sort equity portfolios based on their VRP betas:

$$
\mathrm{VRP}_{i, t}^{\text {beta }}=\frac{\operatorname{Cov}\left[R_{i, t+1}, \operatorname{VRP}_{t+1}^{\text {shock }} \mid \Omega_{t}\right]}{\operatorname{Var}\left[\operatorname{VRP}_{t+1}^{\text {shock }} \mid \Omega_{t}\right]},
$$

where $\mathrm{VRP}_{i, t}^{\text {beta }}$ is the VRP beta of portfolio $i$ in month $t, \operatorname{Cov}\left[R_{i, t+1}, \mathrm{VRP}_{t+1}^{\text {shock }} \mid \Omega_{t}\right]$ is the conditional covariance of portfolio $i$ with $\operatorname{VRP}_{t+1}^{\text {shock }}$ estimated using equation (22), and $\operatorname{Var}\left[\operatorname{VRP}_{t+1}^{\text {shock }} \mid \Omega_{t}\right]$ is the conditional variance of $\operatorname{VRP}_{t+1}^{\text {shock }}$, which is constant in the cross section of equity portfolios.

Ang et al. (2006) test whether the exposure of individual stocks to changes in market volatility predicts cross-sectional variation in future stock returns. They first estimate the exposure of individual stocks to changes in the S\&P 100 index option VXO. Then, they sort stocks into quintile portfolios based on these impliedvolatility betas. They find a negative cross-sectional relation between the volatility betas and future stock returns; that is, stocks with higher (lower) exposure to changes in the VXO generate lower (higher) returns in the next month. Motivated by Ang et al. (2006), we test whether the predictive power of $\operatorname{VRP}_{i, t}^{\text {beta }}$ remains 
intact after controlling for the exposure of equity portfolios to changes in aggregate stock market volatility.

In this section, following Ang et al. (2006), we use the VXO in the estimation of the variance risk premia. We have so far used high-frequency (intraday) market returns to estimate the expected physical variance that enters the VRP, but we use low-frequency returns on the market and equity portfolios to estimate the conditional covariances. To be consistent with the estimation of market variance, VRP, and conditional covariances, in this section, we define the monthly realized variance of the market as the sum of squared daily returns on the S\&P 500 index in a month. Then, we estimate the expected physical variance by regressing the 1-month-ahead realized market variance on the lagged realized market variance and VXO. Because the monthly data on VXO are available from Jan. 1986, our results in this section are based on the sample period Jan. 1986-Dec. 2012.

We start cross-sectional analysis by performing univariate portfolio sorts based on $\mathrm{VRP}_{i, t}^{\text {beta }}$. Then, we present evidence from multivariate cross-sectional regressions with market beta, $\mathrm{VRP}_{i, t}^{\text {beta }}$, and $\mathrm{VXO}_{i, t}^{\text {beta }}$.

Table 4 presents the average excess monthly returns of quintile portfolios that are formed by sorting the 100 size/BM portfolios based on their VRP betas. Q1 (Low VRP ${ }^{\text {beta }}$ ) is the quintile portfolio of size/BM portfolios with the lowest VRP betas during the past month, and Q5 (High VRP ${ }^{\text {beta }}$ ) is the quintile portfolio of size/BM portfolios with the highest VRP betas during the previous month. As shown in the first column of Table 4, the average excess return increases from $0.02 \%$ per month to $0.70 \%$ per month as we move from Q1 to Q5, generating an average return difference of $0.68 \%$ per month between quintile 5 (High VRP ${ }^{\text {beta }}$ ) and quintile 1 (Low VRP ${ }^{\text {beta }}$ ). This return difference is statistically significant with a Newey-West (1987) $t$-statistic of 4.33. In addition to the average excess returns, Table 4 also presents the intercepts (Fama-French (1993) 3-factor alphas,

TABLE 4

Long-Short Equity Portfolios Sorted by VRP Beta

Quintile portfolios are formed every month from Jan. 1990 to Dec. 2012 by sorting 100 size/BM portfolios based on their VRP $^{\text {beta }}$ over the past 1 month. Quintile 1 (Q1) is the portfolio of size/BM portfolios with the lowest VRP beta over the past 1 month. Quintile 5 (Q5) is the portfolio of size/BM portfolios with the highest VRP ${ }^{\text {beta }}$ over the past 1 month. The table reports the average excess monthly returns, the Fama-French (1993) 3-factor alphas (FF3 alpha), and the FamaFrench (1993) and Carhart (1997) 4-factor alphas (FFC4 alpha) on the VRP beta sorted portfolios. The last row presents the differences in monthly returns and the differences in alphas with respect to the 3 -factor and 4 -factor models between quintiles 5 and 1 and the corresponding $t$-statistics. Average excess returns and risk-adjusted returns are given in monthly percentage terms. Newey-West (1987) $t$-statistics are reported below in parentheses.

\begin{tabular}{lccc} 
& Average Excess Return & FF3 Alpha & \multicolumn{1}{c}{ FFC4 Alpha } \\
\cline { 2 - 3 } Q1 & 0.02 & -0.10 & -0.01 \\
Q2 & $(0.06)$ & $(-0.37)$ & $(-0.02)$ \\
& 0.35 & 0.25 & 0.32 \\
Q3 & $(1.34)$ & $(1.03)$ & $(1.25)$ \\
& 0.45 & 0.34 & 0.41 \\
Q4 & $(1.77)$ & $(1.42)$ & $(1.66)$ \\
& 0.53 & 0.41 & 0.48 \\
Q5 & $(2.12)$ & $(1.79)$ & $(2.02)$ \\
& 0.70 & 0.59 & 0.67 \\
High - Low & $(2.94)$ & $(2.67)$ & $(2.97)$ \\
& 0.68 & 0.69 & 0.68 \\
& $(4.33)$ & $(4.99)$ & $(4.09)$ \\
\hline
\end{tabular}


denoted by FF3) from the regression of the average excess portfolio returns on a constant, the excess market return, a size factor (SMB), and a book-to-market factor (HML), following Fama and French (1993). As shown in the last row of Table 4, the difference in FF3 alphas between the High VRP ${ }^{\text {beta }}$ and Low VRP ${ }^{\text {beta }}$ portfolios is $0.69 \%$ per month with a Newey-West $t$-statistic of 4.99 .

The last column of Table 4 presents the alpha of the return differential with respect to a 4-factor model, following Fama and French (1993) and Carhart (1997). Besides the market, size, and book-to-market factors, it includes a fourth factor based on the return differential between stocks in the highest and lowest momentum deciles. The reason for including the fourth factor is to check whether the ability of $\mathrm{VRP}_{i, t}^{\text {beta }}$ to predict returns can be subsumed by the tendency of these equity portfolios to co-move with the momentum factor. ${ }^{18}$ As shown in the last row of Table 4, the difference in the Fama-French (1993) and Carhart (1997) 4-factor alphas (denoted by FFC4) between the High $\operatorname{VRP}_{i, t}^{\text {beta }}$ and Low VRP ${ }_{i, t}^{\text {beta }}$ portfolios is $0.68 \%$ per month with a Newey-West $t$-statistic of 4.09 .

These results indicate that an investment strategy that goes long size/BM portfolios in the highest $\mathrm{VRP}_{i, t}^{\text {beta }}$ quintile and shorts size/BM portfolios in the lowest $\mathrm{VRP}_{i, t}^{\text {beta }}$ quintile produces average raw and risk-adjusted returns of $8.16 \%$ to $8.28 \%$, respectively, per annum. These return and alpha differences are economically and statistically significant at all conventional levels.

To determine whether the cross-sectional predictive power of VRP beta is driven by the outperformance of High VRP ${ }^{\text {beta }}$ portfolios and/or the underperformance of Low VRP ${ }^{\text {beta }}$ portfolios, we compute the FF3 and FFC4 alpha of each quintile portfolio. As reported in Table 4, the FF3 alpha of Q1 is $-0.10 \%$ per month $(t$-statistic $=-0.37)$ and the FFC4 alpha of Q1 is $-0.01 \%$ per month $(t$-statistic $=-0.02)$, presenting an economically and statistically insignificant risk-adjusted return of the short leg of the arbitrage portfolio with Low VRP beta. When we look at the long leg of the arbitrage portfolio with High VRP beta, the FF3 alpha of Q5 is $0.59 \%$ per month with a $t$-statistic of 2.67 and the FFC4 alpha of Q5 is $0.67 \%$ per month with a $t$-statistic of 2.97 . These economically and statistically significant FF3 and FFC4 alphas indicate that the significantly positive link between VRP beta and the cross section of portfolio returns is driven by the outperformance of individual stocks with High VRP beta.

We now examine the cross-sectional relation between VRP beta, market beta, and expected returns using the Fama-MacBeth (1973) regressions. We calculate the time-series averages of the slope coefficients from the regressions of 1-month-ahead portfolio returns on the conditional covariances of portfolios with the market and VRP factors, $\operatorname{Cov}_{t}\left(R_{i, t+1}, R_{m, t+1}\right)$ and $\operatorname{Cov}_{t}\left(R_{i, t+1}, \mathrm{VRP}_{t+1}^{\text {shock }}\right)$. The average slopes provide standard Fama-MacBeth tests for determining whether the market and/or uncertainty factors on average have nonzero premia. Monthly cross-sectional regressions are run for the following asset pricing specification:

$$
\begin{aligned}
R_{i, t+1}= & \lambda_{0, t}+\lambda_{1, t} \cdot \operatorname{Cov}_{t}\left(R_{i, t+1}, R_{m, t+1}\right) \\
& +\lambda_{2, t} \cdot \operatorname{Cov}_{t}\left(R_{i, t+1}, \mathrm{VRP}_{t+1}^{\text {shock }}\right)+\varepsilon_{i, t+1},
\end{aligned}
$$

\footnotetext{
${ }^{18}$ SMB (small minus big), HML (high minus low), and MOM (winner minus loser) are described in and obtained from Kenneth French's data library: http://mba.tuck.dartmouth.edu/pages/ faculty/ken.french/.
} 
where $R_{i, t+1}$ is the excess return on portfolio $i$ in month $t+1$, and $\lambda_{1, t}$ and $\lambda_{2, t}$ are the monthly slope coefficients on $\operatorname{Cov}_{t}\left(R_{i, t+1}, R_{m, t+1}\right)$ and $\operatorname{Cov}_{t}\left(R_{i, t+1}, \mathrm{VRP}_{t+1}^{\text {shock }}\right)$, respectively. The predictive cross-sectional regressions of $R_{i, t+1}$ are run on the time- $t$ expected conditional covariances of portfolios with the market and VRP factors.

Table 5 presents the time-series averages of the slope coefficients $\left(\bar{\lambda}_{1}, \bar{\lambda}_{2}\right)$ over the 324 months from Jan. 1986 to Dec. 2012 for the 100 size/BM portfolios. The bivariate regression results produce a positive and statistically significant relation between $\operatorname{Cov}_{t}\left(R_{i, t+1}, \mathrm{VRP}_{t+1}^{\text {shock }}\right)$ and the cross section of portfolios returns. The average slope, $\bar{\lambda}_{2}$, is estimated to be 0.0250 with a Newey-West (1987) $t$-statistic of 2.94 for the 100 size/BM portfolios. We also find a significantly positive link between market beta and the cross section of expected returns. Specifically, the average slope, $\bar{\lambda}_{1}$, is found to be 3.38 with a $t$-statistic of 2.01 for the 100 size/BM portfolios.

\section{TABLE 5}

Fama-MacBeth Cross-Sectional Regressions

The 1-month-ahead excess returns of the 100 size/BM equity portfolios are regressed every month on the time-varying conditional covariances, $\operatorname{Cov}_{t}\left(R_{i, t+1}, R_{m, t+1}\right), \operatorname{Cov}_{t}\left(R_{i, t+1}, \operatorname{VRP}_{t+1}^{\text {shock }}\right)$, and $\operatorname{Cov}_{t}\left(R_{i, t+1}, \mathrm{VXO}_{t+1}^{\text {shock }}\right)$ to test for the presence and significance of a cross-sectional relation between market beta, VRP beta, and VXO beta:

$$
\begin{aligned}
R_{i, t+1}= & \lambda_{0, t}+\lambda_{1, t} \cdot \operatorname{Cov}_{t}\left(R_{i, t+1}, R_{m, t+1}\right)+\lambda_{2, t} \cdot \operatorname{Cov}_{t}\left(R_{i, t+1}, \mathrm{VRP}_{t+1}^{\text {shock }}\right)+\varepsilon_{i, t+1} \\
R_{i, t+1}= & \lambda_{0, t}+\lambda_{1, t} \cdot \operatorname{Cov}_{t}\left(R_{i, t+1}, R_{m, t+1}\right)+\lambda_{2, t} \cdot \operatorname{Cov}_{t}\left(R_{i, t+1}, \mathrm{VRP}_{t+1}^{\text {shock }}\right) \\
& +\lambda_{3, t} \cdot \operatorname{Cov}_{t}\left(R_{i, t+1}, \mathrm{VXO}_{t+1}^{\text {shock }}\right)+\varepsilon_{i, t+1} .
\end{aligned}
$$

Table 5 reports the average slope coefficients $\left(\bar{\lambda}_{1}, \bar{\lambda}_{2}, \bar{\lambda}_{3}\right)$ from the Fama-MacBeth (1973) regressions and the NeweyWest (1987) $t$-statistics (below in parentheses). The last column presents the average $R^{2}$ values from the monthly crosssectional regressions. The sample period is from Jan. 1990 to Dec. 2012.

\begin{tabular}{lccc}
$\bar{\lambda}_{1}$ & $\bar{\lambda}_{2}$ & $\bar{\lambda}_{3}$ & $R^{2}$ \\
3.3781 & 0.0250 & & $12.94 \%$ \\
$(2.01)$ & $(2.94)$ & & $(10.99)$ \\
0.5099 & 0.0292 & -0.0163 & $16.53 \%$ \\
$(0.26)$ & $(3.61)$ & $(-1.87)$ & $(12.80)$ \\
\hline
\end{tabular}

We now test whether a significantly positive link between VRP beta and expected returns remains intact after controlling for the negative market volatility risk premium. For each month from Jan. 1986 to Dec. 2012, we estimate the following cross-sectional regression specification:

$$
\begin{aligned}
R_{i, t+1}= & \lambda_{0, t}+\lambda_{1, t} \cdot \operatorname{Cov}_{t}\left(R_{i, t+1}, R_{m, t+1}\right)+\lambda_{2, t} \cdot \operatorname{Cov}_{t}\left(R_{i, t+1}, \mathrm{VRP}_{t+1}^{\text {shock }}\right) \\
& +\lambda_{3, t} \cdot \operatorname{Cov}_{t}\left(R_{i, t+1}, \mathrm{VXO}_{t+1}^{\text {shock }}\right)+\varepsilon_{i, t+1} .
\end{aligned}
$$

The second row in Table 5 reports the average slope coefficients $\left(\bar{\lambda}_{1}, \bar{\lambda}_{2}, \bar{\lambda}_{3}\right)$ for the 100 size/BM portfolios. Similar to our finding from the bivariate regression, $\bar{\lambda}_{2}$ is estimated to be positive; $\bar{\lambda}_{2}=0.0292$ with a $t$-statistic of 3.61 , implying a significantly positive uncertainty premium. Consistent with Ang et al. (2006), the average slope on the implied-volatility beta, $\operatorname{Cov}_{t}\left(R_{i, t+1}, \mathrm{VXO}_{t+1}^{\text {shock }}\right)$, is estimated to be negative; $\bar{\lambda}_{3}=-0.0163$ with a $t$-statistic of -1.87 . Interestingly, the average 
slope on market beta, $\operatorname{Cov}_{t}\left(R_{i, t+1}, R_{m, t+1}\right)$, is estimated to be positive but statistically insignificant; $\bar{\lambda}_{1}=0.5099$ with a $t$-statistic of 0.26 . Overall, the results in Table 5 indicate that after controlling for the positive market risk premium and the negative market volatility risk premium, the positive link between VRP beta and expected returns remains highly significant.

\section{Conclusion}

Although uncertainty is more common in the decision-making process than risk, relatively little attention is paid to the phenomenon of uncertainty in empirical asset pricing literature. This paper focuses on economic uncertainty and augments the original consumption-based asset pricing models to introduce a 2-factor conditional asset pricing model with time-varying market risk and uncertainty. According to the augmented asset pricing model, the premium on equity is composed of two separate terms; the first term compensates for the market risk, and the second term represents a true premium for economic uncertainty. We use the conditional asset pricing model to test whether the time-varying conditional covariances of equity returns with the market and uncertainty factors predict their future returns.

Because information about economic uncertainty is too imprecise to measure with available data, we have to come up with a proxy for uncertainty that should be consistent with the investment opportunity set of risk-averse investors. Following Zhou (2009), we measure economic uncertainty with the VRP of the aggregate stock market portfolio. Different from earlier studies, we provide empirical evidence that the VRP is indeed closely related to economic and financial market uncertainty. Specifically, we generate several proxies for uncertainty based on the macroeconomic variables, return distributions of financial firms, CDS market, and investors' disagreement about individual stocks. We show that the VRP is highly correlated with all measures of uncertainty.

Based on the 2-factor asset pricing model, we investigate whether the market prices of risk and uncertainty are economically and statistically significant in the U.S. equity market. Using the DCC model of Engle (2002), we estimate equity portfolios' conditional covariances with the market portfolio and VRP factors and then test whether these dynamic conditional covariances predict future returns on equity portfolios. The empirical results from the size, book-to-market, momentum, and industry portfolios indicate that the DCC-based conditional covariances of equity portfolios with the market and VRP factors predict the time-series and cross-sectional variation in stock returns. We find the risk-return coefficients to be positive and highly significant, implying a strongly positive link between expected return and market risk. Similarly, the results indicate a significantly positive market price of uncertainty. That is, equity portfolios that are highly correlated with uncertainty (proxied by the VRP) carry a significant premium relative to portfolios that are uncorrelated or minimally correlated with VRP. In addition to the size, book-to-market, momentum, and industry portfolios, we investigate the significance of risk, uncertainty, and return trade-offs using the largest 500 stocks trading at the NYSE, AMEX, and NASDAQ, as well as stocks in the S\&P 500 index. Consistent with our findings from equity portfolios, we find significantly 
positive market prices of risk and uncertainty for large stocks trading in the U.S. equity market.

We also examine whether the conditional covariances with the VRP could be picking up the covariances with market volatility, market illiquidity, and default risk. We find that the significantly positive link between uncertainty and future returns remains intact after controlling for market volatility, liquidity, and credit risk.

Finally, we investigate the cross-sectional asset pricing performance of our model using the long-short equity portfolios and the Fama-MacBeth (1973) regressions. The results indicate that the annual average raw and risk-adjusted returns of the equity portfolios in the highest VRP beta quintile are about $8 \%$ higher than the annual average returns of the equity portfolios in the lowest VRP beta quintile. After controlling for the market, size, book-to-market, and momentum factors of Fama and French (1973) and Carhart (1997), the positive relation between VRP beta and the cross section of portfolio returns remains economically and statistically significant. Overall, we conclude that the time-varying exposures of equity portfolios to the variance risk premia predict the time-series and crosssectional variation in stock returns.

\section{References}

Aielli, G. P. "Dynamic Conditional Correlation: On Properties and Estimation.” Journal of Business and Economic Statistics, 31 (2013), 282-299.

Allen, L.; T. G. Bali; and Y. Tang. "Does Systemic Risk in the Financial Sector Predict Future Economic Downturns?” Review of Financial Studies, 25 (2012), 3000-3036.

Anderson, E. W.; E. Ghysels; and J. L. Juergens. "The Impact of Risk and Uncertainty on Expected Returns.” Journal of Financial Economics, 94 (2009), 233-263.

Andreou, E.; E. Ghysels; and A. Kourtellos. "Regression Models with Mixed Sampling Frequencies." Journal of Econometrics, 158 (2010), 246-261.

Ang, A.; R. Hodrick; Y. Xing; and X. Zhang. "The Cross-Section of Volatility and Expected Returns." Journal of Finance, 61 (2006), 259-299.

Bakshi, G., and N. Kapadia. "Delta-Hedged Gains and the Negative Market Volatility Risk Premium." Review of Financial Studies, 16 (2003), 527-566.

Bakshi, G., and D. Madan. "A Theory of Volatility Spread." Management Science, 52 (2006), 1945-1956.

Bali, T. G. "The Intertemporal Relation between Expected Returns and Risk." Journal of Financial Economics, 87 (2008), 101-131.

Bali, T. G., and R. F. Engle. "The Intertemporal Capital Asset Pricing Model with Dynamic Conditional Correlations.” Journal of Monetary Economics, 57 (2010), 377-390.

Bates, D. S. "Jumps and Stochastic Volatility: Exchange Rate Process Implicit in Deutsche Mark Options." Review of Financial Studies, 9 (1996), 69-107.

Bekaert, G., and E. Engstrom. "Asset Return Dynamics under Bad Environment-Good Environment Fundamentals.” Working Paper, Columbia University and Federal Reserve Board (2010).

Bekaert, G.; E. Engstrom; and Y. Xing. "Risk, Uncertainty, and Asset Prices." Journal of Financial Economics, 91 (2009), 59-82.

Bekaert, G.; M. Hoerova; and M. L. Duca. "Risk, Uncertainty and Monetary Policy." Journal of Monetary Economics, 60 (2013), 771-788.

Bollerslev, T. "Generalized Autoregressive Conditional Heteroskedasticity." Journal of Econometrics, 31 (1986), 307-327.

Bollerslev, T.; R. F. Engle; and J. M. Wooldridge. "A Capital Asset Pricing Model with Time-Varying Covariances." Journal of Political Economy, 96 (1988), 116-131.

Bollerslev, T.; M. Gibson; and H. Zhou. "Dynamic Estimation of Volatility Risk Premia and Investor Risk Aversion from Option-Implied and Realized Volatilities." Journal of Econometrics, 160 (2011), 102-118.

Bollerslev, T.; G. Tauchen; and H. Zhou. "Expected Stock Returns and Variance Risk Premia." Review of Financial Studies, 22 (2009), 4463-4492. 
Bollerslev, T., and V. Todorov. "Tails, Fears and Risk Premia." Journal of Finance, 66 (2011), 2165-2211.

Britten-Jones, M., and A. Neuberger. "Option Prices, Implied Price Processes, and Stochastic Volatility." Journal of Finance, 55 (2000), 839-866.

Buraschi, A.; F. Trojani; and A. Vedolin. "When Uncertainty Blows in the Orchard: Comovement and Equilibrium Volatility Risk Premia.” Journal of Finance, 69 (2014), 101-137.

Campbell, J. Y. "Intertemporal Asset Pricing without Consumption Data." American Economic Review, 83 (1993), 487-515.

Campbell, J. Y. “Understanding Risk and Return.” Journal of Political Economy, 104 (1996), 298-345.

Campbell, J. Y.; S. Giglio; C. Polk; and R. Turley. "An Intertemporal CAPM with Stochastic Volatility." Working Paper, Harvard University (2014).

Campbell, J. Y., and R. J. Shiller. "The Dividend-Price Ratio and Expectations of Future Dividends and Discount Factors." Review of Financial Studies, 1 (1988), 195-228.

Campbell, S. D., and F. X. Diebold. "Stock Returns and Expected Business Conditions: Half a Century of Direct Evidence." Journal of Business and Economic Statistics, 27 (2009), 266-278.

Caporin, M., and M. McAleer. "Ten Things You Should Know about the Dynamic Conditional Correlation Representation." Econometrics, 1 (2013), 115-126.

Carhart, M. M. “On Persistence in Mutual Fund Performance.” Journal of Finance, 52 (1997), 57-82.

Carr, P., and L. Wu. "Variance Risk Premiums." Review of Financial Studies, 22 (2009), 1311-1341.

Chen, Z., and L. G. Epstein. "Ambiguity, Risk, and Asset Returns in Continuous Time.” Econometrica, 4 (2002), 1403-1445.

Diether, K.; C. Malloy; and A. Scherbina. "Differences of Opinion and the Cross-Section of Stock Returns." Journal of Finance, 57 (2002), 2113-2141.

Drechsler, I., and A. Yaron. "What's Vol Got to Do with It?" Review of Financial Studies, 24 (2011), $1-45$.

Driessen, J.; P. J. Maenhout; and G. Vilkov. "The Price of Correlation Risk: Evidence from Equity Options.” Journal of Finance, 64 (2009), 1377-1406.

Ellsberg, D. "Risk, Ambiguity, and the Savage Axiom." Quarterly Journal of Economics, 75 (1961), 643-669.

Engle, R. F. "Dynamic Conditional Correlation: A Simple Class of Multivariate Generalized Autoregressive Conditional Heteroskedasticity Models." Journal of Business and Economic Statistics, 20 (2002), 339-350.

Epstein, L. G. “A Definition of Uncertainty Aversion.” Review of Economic Studies, 66 (1999), 679-708.

Epstein, L. G., and T. Wang. "Intertemporal Asset Pricing under Knightian Uncertainty.” Econometrica, 62 (1994), 283-322.

Epstein, L. G., and J. Zhang. "Subjective Probabilities on Subjectively Unambiguous Events." Econometrica, 69 (2001), 265-306.

Fama, E. F., and K. R. French. "The Cross-Section of Expected Stock Returns.” Journal of Finance, 47 (1992), 427-465.

Fama, E. F., and K. R. French. "Common Risk Factors in the Returns on Stocks and Bonds." Journal of Financial Economics, 33 (1993), 3-56.

Fama, E. F., and J. MacBeth. "Risk, Return, and Equilibrium: Empirical Tests." Journal of Political Economy, 71 (1973), 607-636.

Gabaix, X. "Variable Rare Disasters: An Exactly Solved Framework for Ten Puzzles in MacroFinance." Quarterly Journal of Economics, 127 (2012), 645-700.

Ghysels, E.; P. Santa-Clara; and R. Valkanov. "There Is a Risk-Return Trade-Off after All." Journal of Financial Economics, 76 (2005), 509-548.

Ghysels, E.; A. Sinko; and R. Valkanov. "MIDAS Regressions: Further Results and New Directions." Econometric Review, 26 (2006), 53-90.

Glosten, L. R.; R. Jagannathan; and D. E. Runkle. "On the Relation between the Expected Value and the Volatility of the Nominal Excess Returns on Stocks." Journal of Finance, 48 (1993), 1779-1801.

Goetzmann, W. N.; A. Watanabe; and M. Watanabe. "Investor Expectations, Business Conditions, and the Pricing of Beta-Instability Risk." Working Paper, Yale University (2009).

Guo, H., and R. Savickas. "Idiosyncratic Volatility, Stock Market Volatility, and Expected Stock Returns." Journal of Business and Economic Statistics, 24 (2006), 43-56.

Guo, H., and R. F. Whitelaw. "Uncovering the Risk-Return Relation in the Stock Market." Journal of Finance, 61 (2006), 1433-1463.

Jegadeesh, N., and S. Titman. "Returns to Buying Winners and Selling Losers: Implications for Stock Market Efficiency.” Journal of Finance, 48 (1993), 65-91.

Jiang, G., and Y. Tian. "Model-Free Implied Volatility and Its Information Content." Review of Financial Studies, 18 (2005), 1305-1342. 
Ju, N., and J. Miao. "Ambiguity, Learning, and Asset Returns.” Econometrica, 80 (2012), 559-591.

Kelly, B. T. "Tail Risk and Asset Prices." Review of Financial Studies, 27 (2014), 2841-2871.

Klibanoff, P.; M. Marinacci; and S. Mukerji. "A Smooth Model of Decision Making under Ambiguity." Econometrica, 73 (2005), 1849-1892.

Lundblad, C. "The Risk Return Tradeoff in the Long Run: 1836-2003." Journal of Financial Economics, 85 (2007), 123-150.

Maccheroni, F.; M. Marinacci; and A. Rustichini. "Ambiguity Aversion, Robustness, and the Variational Representation of Preferences." Econometrica, 74 (2006), 1447-1498.

Merton, R. C. "An Intertemporal Capital Asset Pricing Model." Econometrica, 41 (1973), 867-887.

Newey, W. K., and K. D. West. "A Simple Positive Semi-Definite, Heteroskedasticity and Autocorrelation Consistent Covariance Matrix." Econometrica, 55 (1987), 703-708.

Noureldin, D.; N. Shephard; and K. Sheppard. "Multivariate Rotated ARCH Models." Journal of Econometrics, 179 (2014), 16-30.

Pan, J. "The Jump-Risk Premia Implicit in Options: Evidence from an Integrated Time-Series Study." Journal of Financial Economics, 63 (2002), 3-50.

Rosenberg, J. V., and R. F. Engle. "Empirical Pricing Kernels." Journal of Financial Economics, 64 (2002), 341-372.

Schmeidler, D. "Subjective Probability and Expected Utility without Additivity." Econometrica, 57 (1989), 571-587.

Todorov, V. "Variance Risk Premium Dynamics: The Role of Jumps." Review of Financial Studies, 23 (2010), 345-383.

Zhou, H. "Variance Risk Premia, Asset Predictability Puzzles, and Macroeconomic Uncertainty." Working Paper, Federal Reserve Board (2009). 